Portland State University

PDXScholar

Mechanical and Materials Engineering Faculty

Publications and Presentations

Mechanical and Materials Engineering

3-31-2016

\title{
More Investigations in Capillary Fluidics Using a Drop Tower
}

\author{
Andrew Paul Wollman \\ Portland State University, drew.wollman@gmail.com \\ Mark M. Weislogel \\ Portland State University, weisloge@pdx.edu \\ Brentley M. Wiles \\ Portland State University \\ Donald Pettit \\ NASA Johnson Space Center \\ Trevor Snyder \\ 3D Systems
}

Follow this and additional works at: https://pdxscholar.library.pdx.edu/mengin_fac

Part of the Fluid Dynamics Commons, and the Materials Science and Engineering Commons Let us know how access to this document benefits you.

\section{Citation Details}

Wollman, A., Weislogel, M., Wiles, B., Pettit, D., \& Snyder, T. (2016). More investigations in capillary fluidics using a drop tower. Experiments in Fluids, 57(4), 1-17.

This Article is brought to you for free and open access. It has been accepted for inclusion in Mechanical and Materials Engineering Faculty Publications and Presentations by an authorized administrator of PDXScholar. Please contact us if we can make this document more accessible: pdxscholar@pdx.edu. 


\title{
More investigations in capillary fluidics using a drop tower
}

\author{
Andrew Wollman ${ }^{1} \cdot$ Mark Weislogel $^{1} \cdot$ Brently Wiles $^{1} \cdot$ Donald Pettit $^{2}$. \\ Trevor Snyder ${ }^{3}$
}

Received: 1 December 2015 / Revised: 2 February 2016 / Accepted: 5 February 2016 / Published online: 30 March 2016

(C) Springer-Verlag Berlin Heidelberg 2016

\begin{abstract}
A variety of contemplative demonstrations concerning intermediate-to-large length scale capillary fluidic phenomena were made possible by the brief weightless environment of a drop tower (Wollman and Weislogel in Exp Fluids 54(4):1, 2013). In that work, capillarity-driven flows leading to unique spontaneous droplet ejections, bubble ingestions, and multiphase flows were introduced and discussed. Such efforts are continued herein. The spontaneous droplet ejection phenomena (auto-ejection) is reviewed and demonstrated on earth as well as aboard the International Space Station. This technique is then applied to novel low-g droplet combustion where soot tube structures are created in the wakes of burning drops. A variety of new tests are presented that routinely demonstrate 'puddle jumping,' a process defined as the spontaneous recoil and ejection of large liquid drops from hydrophobic surfaces following the step reduction in 'gravity' characteristic of most drop towers. The inverse problem of 'bubble jumping' is also demonstrated for the case of hydrophilic surfaces. A variety of puddle jump demonstrations are presented in summary as a means of suggesting the further exploitation of drop towers to study such large length scale capillary phenomena.
\end{abstract}

NASA cooperative agreement NNX09AP66A and NASA/Oregon Space Grant Consortium grant NNX10AK68H.

Andrew Wollman

drew.wollman@gmail.com

Mark Weislogel

mmw@mme.pdx.edu

1 Portland State University, Portland, OR, USA

2 NASA, Johnson Space Center, Houston, TX, USA

3 3D Systems, Willsonville, OR, USA

\section{Introduction}

In a previous article by Wollman and Weislogel (2013), a variety of new observations are demonstrated that exploit the unique characteristics of a drop tower as an experimental facility for the study of capillary macrofluidics, including large length scale capillary fluidics. As briefly reviewed in that article, a drop tower provides a near step reduction in effective gravity level allowing for a wide range of often unearthly observations of large length scale capillary phenomena. Unique balances of inertia and surface tension forces permit observations of enormous systems despite the short duration usually afforded by a drop tower (i.e., typically $<10 \mathrm{~s}$ ) (Steinberg 2008; Chunhui 1993; Dittus 1991; Suñol and González-Cinca 2011; Lekan et al. 1993; Wollman and Weislogel 2013; Meseguer et al. 2014; Wollman 2012. For example, in the absence of significant body forces (Bond number $\mathrm{Bo}=\rho g R^{2} / \sigma \ll 1$ ) a balance of inertia and capillarity gives $R_{\mathrm{DT}} \sim\left(\sigma t_{\mathrm{DT}}^{2} / \rho\right)^{1 / 3}$, where $R_{\mathrm{DT}}$ is the maximum characteristic dimension of the capillary surface, $\sigma$ is the surface tension, $\rho$ is the density difference across the fluid interface, $g$ is the local acceleration level, and $t_{\mathrm{DT}}$ is the effective free fall time of the drop tower. $R_{\mathrm{DT}}$ is the largest sized system that one might expect to observe a capillary response in the drop time available $t_{\mathrm{DT}}$. Liquid volumes participating are estimated via $V_{\mathrm{DT}} \sim R_{\mathrm{DT}}^{3}=\sigma t_{\mathrm{DT}}^{2} / \rho$. For water in our drop tower with $t_{\mathrm{DT}}=2.1 \mathrm{~s}$ (Dryden Drop Tower Wollman 2012), we estimate $R_{\mathrm{DT}} \sim 65 \mathrm{~mm}$ such that $V_{\mathrm{DT}} \sim 300 \mathrm{ml}$. This volume is 10,000 times larger than a large raindrop, where $V_{1 g} \sim 0.03 \mathrm{ml}$ (assuming $R_{1 g}=2 \mathrm{~mm}$ ). In this way, 'enormous' capillary fluidic bodies may be studied using drop towers for both fundamental and applied purposes. 
Additionally, and perhaps undervalued, the slow response of the large-scale systems allow routine high-definition imaging with low-cost commercial cameras as measured by the time-response ratio $\left(\sim R_{\mathrm{DT}} / R_{1 g}\right)^{3 / 2} \approx(65 / 2)^{3 / 2}=185$. For example, video images presented herein are recorded between 60 and $15,000 \mathrm{fps}$. The effective frame rates required for such tests conducted in a terrestrial environment $(\times 185)$ are approximately 11,000 and 2,800,000 fps, respectively. The latter frame rates at high definition are currently prohibitive to most investigators. Thus, aspects of complex dynamic phenomena such as interface breakup, rupture, de-wetting, impacts, splashing, rebounds may be far easier to resolve employing large capillary systems in low-gravity environments. Of course applied investigations of large length scale capillary phenomena are appropriate for any system expected to experience low-g such as fluid systems aboard spacecraft.

In the previous work (Wollman and Weislogel 2013), a drop tower is used to demonstrate several unique capillary fluidic effects that might be further exploited for subsequent study: spontaneous drop ejection ('autoejection'), bubble ingestion ('auto-ingestion'), particle injection from liquid surfaces, particle ejection from liquid surfaces, and a variety of passively generated twophase flows. In this continuation, we provide additional highlights of auto-ejection before demonstrating how it might be used to study other phenomena such as low-g 'sprays' and droplet combustion. We then provide new demonstrations of droplet ejection from hydrophobic surfaces. Because such drops can be quite large, we dub such phenomena as 'puddle jumping' or 'jumping puddles'. Applications of the jumping puddle phenomena as a means of spontaneous on-demand drop deployment may be obvious to most readers. We, nonetheless, provide a variety of demonstrations supportive of droplet management, droplet impact, and containerless processing investigations.

\section{Auto-droplet ejection (auto-ejection)}

It has been shown that spontaneous rise in a capillary tube can lead to the auto-ejection of droplets if the tube contains a nozzle (Wollman 2012; Wollman and Weislogel 2013). Figure 1 details a typical auto-ejection drop tower test. A circular tube partially submerged in a reservoir of perfectly wetting (contact angle $\theta=0^{\circ}$ ) polydimethylsiloxane (PDMS) is placed on a stage between a light source and a HD camera. Upon a step reduction in gravity, liquid rises along the tube, is accelerated in a nozzle, and emits a short jet which ruptures ejecting a single drop. Different tube and nozzle dimensions and geometries produce a variety of ejection types, as will be shown. Test fluid properties and tube dimensions employed are listed in Tables 1 and 2.

As shown in Fig. 2, transient jets producing single, double, and up to 6 or more drops may be produced in such flows for a variety of fluid properties and tube dimensions provided the Weber number We $\equiv \rho U^{2} R / \sigma \gtrsim 12 / C^{3}$, where $U$ is the characteristic fluid velocity, $R$ is the tube radius, and $C=R_{n} / R$ is the ratio of nozzle radius to tube radius. Such flows have been subsequently investigated numerically by Mehrabian and Feng (2014) who suggest We $>3.4 f\left(L_{\mathrm{e}}\right)$, where $f\left(L_{\mathrm{e}}\right)=1+0.8 / L_{\mathrm{e}}$, the effective length $L_{\mathrm{e}}=R C(1-C)^{2} / \tan \alpha+C^{2}(L+7 R / 6)$, and $\alpha$ is the nozzle contraction angle. As shown in Fig. 3, the autoejection of drops of volume as low as $1.7 \mathrm{nl}$ at $1.12 \mathrm{~m} / \mathrm{s}$ (indicated by arrow) has been demonstrated in terrestrial experiments and up to $\approx 2.6-\mathrm{ml}$ drops at $0.076 \mathrm{~m} / \mathrm{s}$ have been achieved in tests performed aboard the International Space Station. As highlighted in Wollman and Weislogel (2013), a wide range of drop volumes between $6 \mathrm{nl}$ and $1.0 \mathrm{ml}$ and ejection velocities between 0.005 and $2.4 \mathrm{~m} / \mathrm{s}$ are reported for drop tower tests conducted to date. The complexities of high-rate auto-ejection phenomena are well illustrated in the single-drop test of Fig. 4, where a concave nozzle produces a single primary $0.97 \mathrm{ml}$ droplet ejection preceded by ingestion of a gas bubble and much smaller high-speed capillary wave induced drop ejections of order 0.006 to $0.6 \mu \mathrm{l}$. A cascade of drop sizes and velocities is observed in such cases. Mehrabian and Feng (2014) suggest preliminary ejection occurs for nozzle contraction angles $\alpha \geq 45^{\circ}$. We show qualitative agreement in Fig. 4; however, the velocities of the jet and preliminary droplet ejections are greater in number and orders of magnitude faster and smaller than those numerically modeled. Repeat results for 10 nearly identical tests are shown immediately after pinch off in Fig. 5 for 5 cSt PDMS in a 60-mm-long, 20.2-mm ID tube with 10-mm-diameter nozzle (see Table 2). For these conditions, nearly stationary $(\lesssim 0.01 \mathrm{~m} / \mathrm{s})$ ejected drops of volume $2.11 \pm 0.13 \mathrm{ml}$ are ejected $1.77 \pm 0.08 \mathrm{~s}$ into tests.

\section{Sample auto-ejection demonstrations}

\subsection{Droplet swarms}

With the general auto-ejection design guidelines in hand, passive droplet ejectors may be developed for any number of drop tower investigations. For example, in Fig. $6 a$ an FDM 3D-printed ABS $10 \times 10$ nozzle array generates over 400 droplets for a low-g spray study (Snyder et al. 2014). In Fig. 6b, c the same array is employed to investigate drop swarm impacts on smooth and textured surfaces, respectively. Data from such tests provides statistical information for the design of droplet-laden flows common 


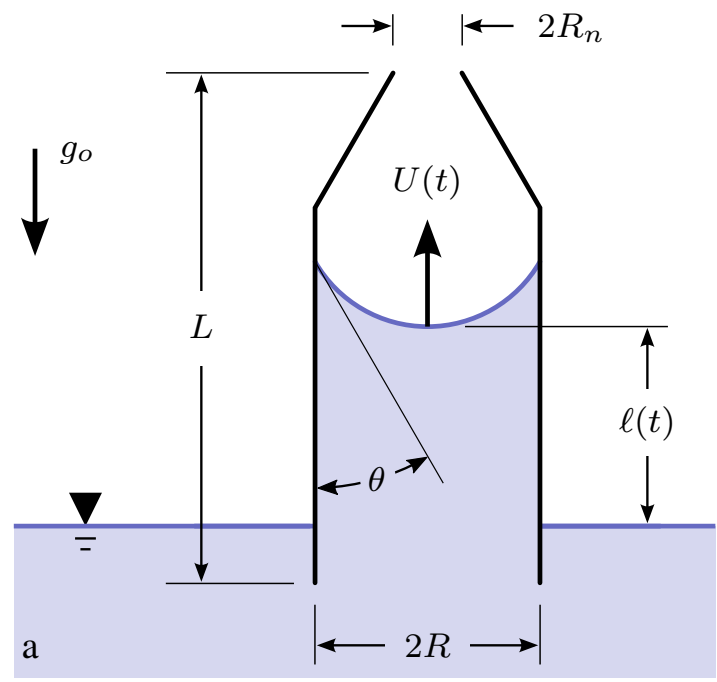

$20 \mathrm{~mm}$
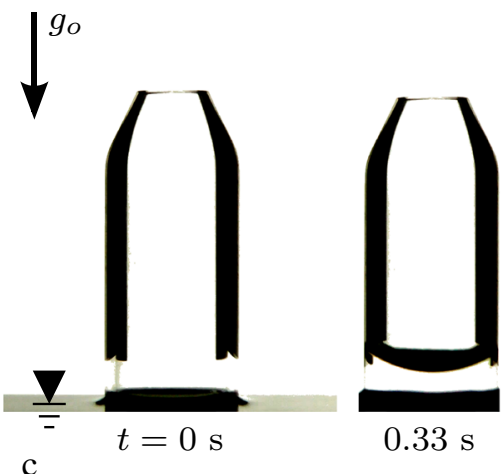

$0.33 \mathrm{~s}$

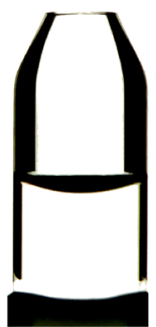

$0.66 \mathrm{~s}$

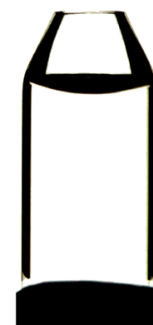

$1.00 \mathrm{~s}$

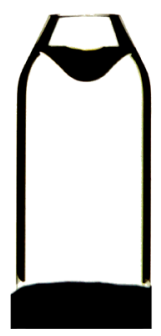

$1.08 \mathrm{~s}$

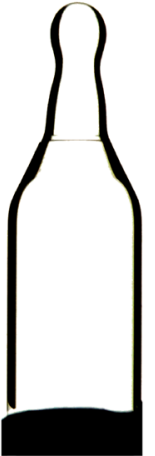

$1.33 \mathrm{~s}$
5

4

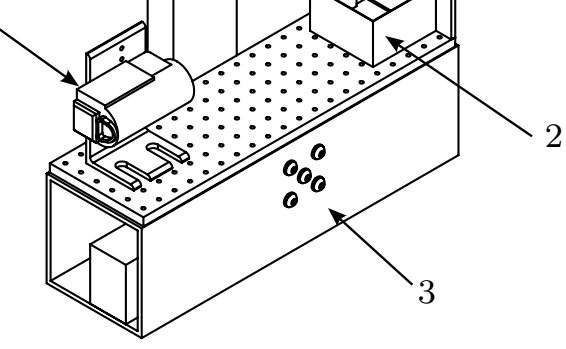

b

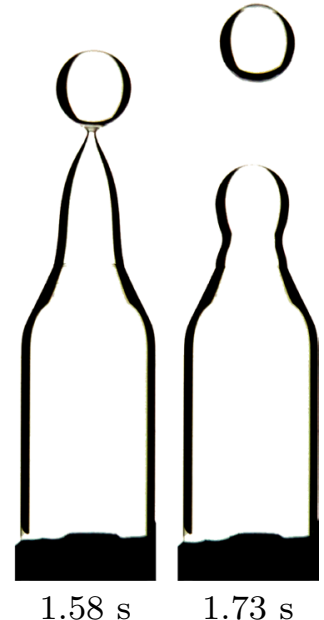

Fig. 1 Schematic of flow geometry (a), experiment setup (b), and image sequence (c) of a typical droplet ejection drop tower test. a A circular tube of length $L$ and radius $R$ with a nozzle of radius $R_{n}$ is partially submerged in a liquid bath of test fluid with contact angle $\theta$. Upon the step reduction in gravity $g_{o}$ liquid will rise along the tube $\ell(t)$ at a mean velocity $U(t)$. b The partially submerged tube is (1) centered in a liquid bath (2) placed on the experiment rig (3) between the camera (4) and backlight (5). (c) Image sequence of perfectly wetting 2 cSt PDMS rising along tube number 1 (Table 2), accelerating in the nozzle, and auto-ejecting a jet which pinches off a single $0.66-\mathrm{ml}$ droplet traveling at $0.07 \mathrm{~m} / \mathrm{s}$
Table 1 Nominal properties of test fluids polydimethylsiloxane (PDMS) and water

\begin{tabular}{lllll}
\hline Fluid & $\nu \pm 2 \%(\mathrm{cSt})$ & $\rho \pm 5 \%\left(\mathrm{~kg} / \mathrm{m}^{3}\right)$ & $\sigma \pm 5 \%\left(\mathrm{~kg} / \mathrm{s}^{2}\right)$ & $\mu(\mathrm{kg} / \mathrm{m} \mathrm{s})$ \\
\hline PDMS (Corning 1998) & 0.65 & 760 & 0.0159 & 0.000494 \\
PDMS (Corning 1998) & 1 & 816 & 0.0174 & 0.000816 \\
PDMS (Corning 1998) & 2 & 872 & 0.0187 & 0.001744 \\
PDMS (Corning 1998) & 5 & 913 & 0.0197 & 0.004565 \\
PDMS (Corning 1998) & 10 & 935 & 0.0201 & 0.00935 \\
PDMS (Corning 1998) & 20 & 949 & 0.0206 & 0.01898 \\
Water (20 $\left.{ }^{\circ} \mathrm{C}\right)$ (White and Corfield 2006) & 1 & 998 & 0.0727 & 0.001002 \\
\hline
\end{tabular}

in life-support systems for spacecraft such as condensing heat exchangers and spacecraft firefighting equipment. Nozzle arrays with tube diameter and tube length distributions provide a wide range of simultaneous drop vectors, velocities, densities, diameters, temporal distributions, and more. 
Table 2 Dimensional details for tubes used in auto-ejection tests

\begin{tabular}{|c|c|c|c|c|c|c|c|}
\hline Tube no. & Tube material & $\begin{array}{l}\text { Tube length } L \\
\text { (mm) }\end{array}$ & $\begin{array}{l}\text { Tube radius } R \\
(\mathrm{~mm})\end{array}$ & $\begin{array}{l}\text { Nozzle radius } R_{n} \\
(\mathrm{~mm})\end{array}$ & Radius ratio $C$ & $\begin{array}{l}\text { Contraction } \\
\text { angle } \alpha\left(^{\circ}\right)\end{array}$ & Figures \\
\hline 1 & Glass & 60.4 & 10.1 & 5.0 & 0.5 & 31 & Figures $1 \mathrm{c}$ and 5 \\
\hline 2 & Polystyrene & 62.3 & 5.1 & 3.6 & 0.7 & 8 & Figure 2 \\
\hline 3 & Polystyrene & 57.5 & 5.1 & 2.9 & 0.6 & 8 & \\
\hline 4 & Polystyrene & 70.4 & 5.1 & 2.1 & 0.4 & 8 & \\
\hline 5 & Polystyrene & 72.9 & 5.1 & 1.4 & 0.3 & 8 & \\
\hline 6 & Glass & 5.0 & 0.8 & 0.4 & 0.5 & 43 & Figure $3 a$ \\
\hline 7 & Glass & 110.0 & 12.5 & 5.0 & 0.4 & 15 & Figure $3 b$ \\
\hline 8 & Glass & 51.5 & 7.3 & 3.8 & 0.5 & 44 & Figure 4 \\
\hline 9 & ABS & 60.4 & 2.5 & 1.5 & 0.6 & 90 & Figure 6 \\
\hline
\end{tabular}

Fig. 2 Four nozzle geometries simultaneously auto-ejecting 0.65 cSt PDMS $1.08 \mathrm{~s}$ into a single-drop tower test. Tube numbers listed correspond to those referenced in Table 2

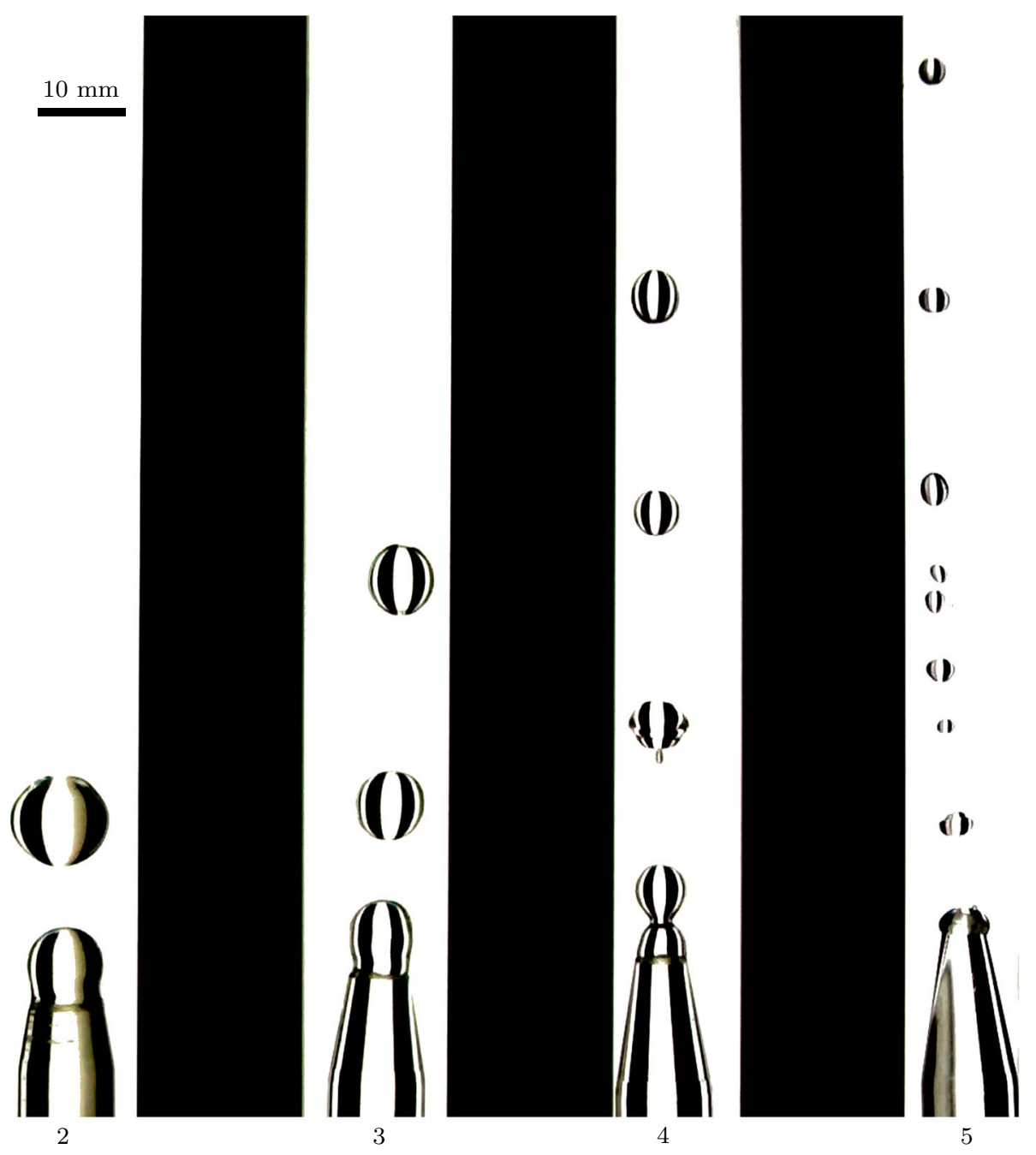

\subsection{Droplet combustion}

Because auto-ejection is simple, passive, and highly repeatable, it is an obvious choice as a method for droplet deployment in low-g drop tower investigations. As an example, we highlight an application of the method to the study of translating droplet combustion. Figure 7 details the components and dimensions of an asymmetric U-tube channel used to auto-eject droplets horizontally. The tube is a rectangular passageway created by stacking 5 laser cut 


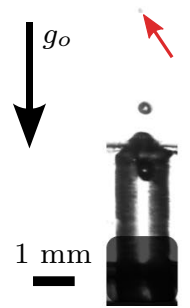

a

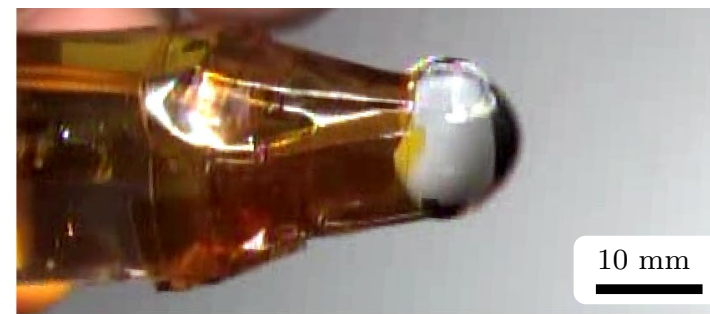

b
Fig. 3 Sample breadth of auto-ejection from tests performed at (a) $1 \mathrm{~g}$ and (b) aboard the International Space Station (ISS). a A $1.7 \mathrm{nl}$ PDMS droplet (arrow) ejected at $1.12 \mathrm{~m} / \mathrm{s}$ followed by a $36 \mathrm{nl}$ droplet ejected at $0.106 \mathrm{~m} / \mathrm{s}$ on bench top terrestrial experiment using small tube number 6. A bubble is entrapped near the nozzle entrance. b A 2.6- $\mathrm{ml}$ water droplet ejected at $0.076 \mathrm{~m} / \mathrm{s}$ from tube number 7 , which was manufactured aboard the ISS by NASA astronaut Don Pettit during Expedition 30/31

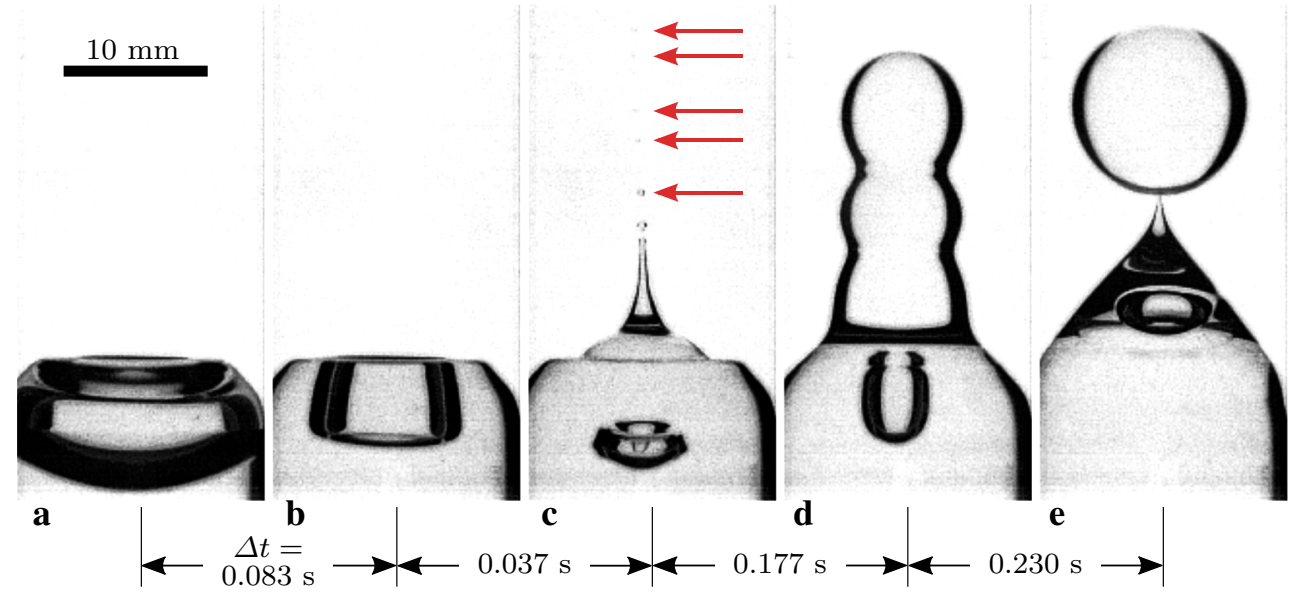

Fig. 4 Perfectly wetting $0.65 \mathrm{cSt}$ PDMS (a) rises spontaneously along tube number 9 during a drop tower test. b The contact line pins at the outlet of the 3.6-mm-long, 7.5-mm-diameter circular nozzle. The rising column of liquid behind the meniscus flattens the meniscus, and a capillary-generated inertial wave travels radially inward toward the center of the tube at $\sim 0.9 \mathrm{~m} / \mathrm{s}$. c The wave collides with itself, constructively interferes, traps a bubble in the nozzle, and shoots two opposing liquid jets (geysers) parallel to the tube axis. The jet shot downward into the bubble is rapidly damped by the rising liquid. The jet shot upward out of the tube travels $2.4 \mathrm{~m} / \mathrm{s}$ and pinches off into roughly 10 each $\mathcal{O}(0.006-0.6 \mu l)$ droplets (arrows indicate first 5). We call this event 'capillary-inertial-wave ejection' as commonly observed in forced drop/jet printing operations. d Meanwhile, the bulk liquid flow accelerates in the nozzle via Bernoulli's principle, overpowers the surface tension forces now acting in the opposite direction due to the inverted meniscus, and produces a 17.4-mm-long jet of liquid that breaks up into (e) a single $0.97 \mathrm{ml}$ drop traveling at $0.01 \mathrm{~m} / \mathrm{s}$. Image sequence taken from camera footage captured at $15,000 \mathrm{fps}$
Fig. 5 First frame after pinch off of repeat tests showing ejected $2.11 \pm 0.13 \mathrm{ml} 5 \mathrm{cSt}$ PDMS droplets auto-ejected from tube number 1 . Pinch off occurs at $1.77 \pm 0.08 \mathrm{~s}$ into tests

\section{$20 \mathrm{~mm}$}

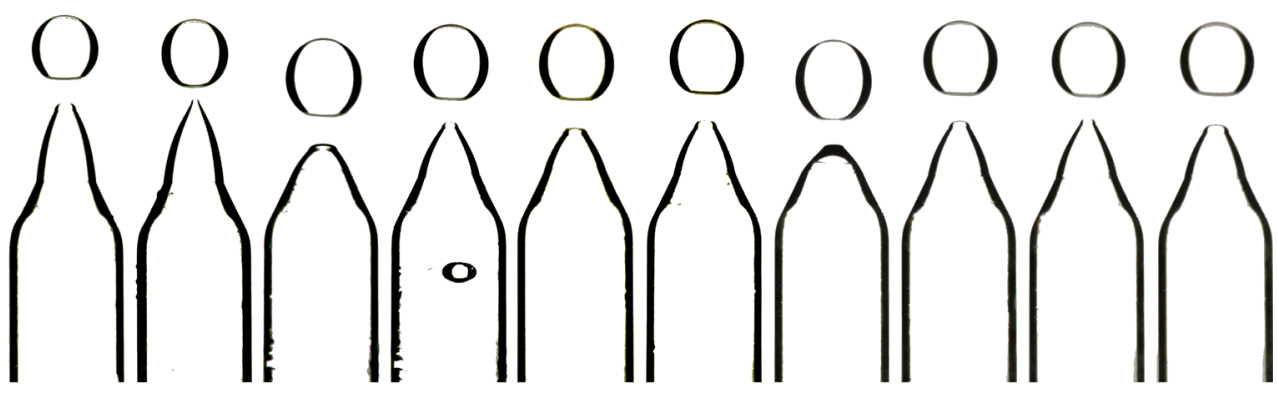




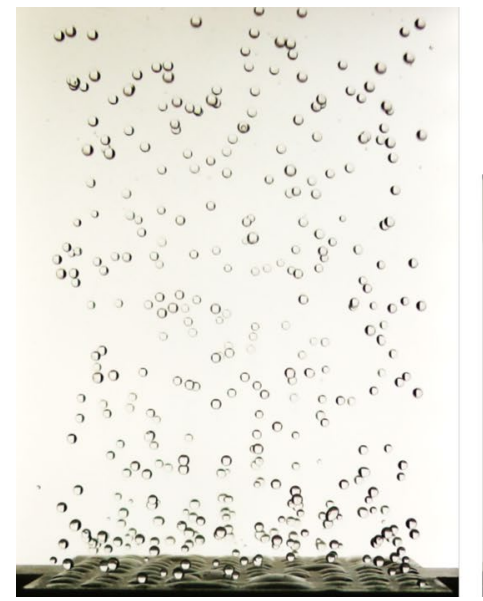

a

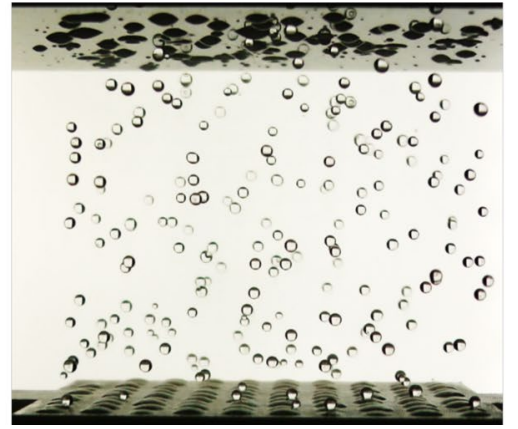

b

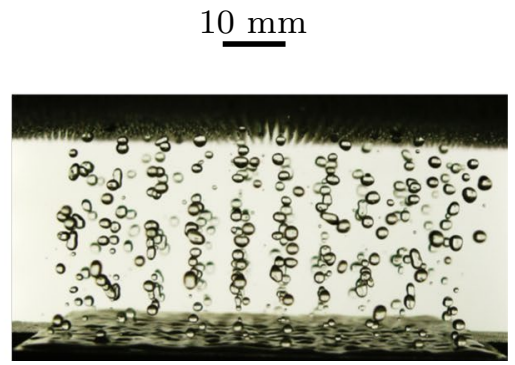

c
Fig. 6 a Droplet swarm of $0.65 \mathrm{cSt}$ PDMS auto-ejected from a $10 \times 10$ array of 3D-printed $60.4 \mathrm{~mm}$-long, 5-mm ID tubes capped with 3-mm-diameter nozzles (tube number 9) produced by liquid jets that break up into approximately $4-$ to $4.2-\mu 1$ droplets. Image at $1.02 \mathrm{~s}$ into drop tower test. b Droplet swarm of $2 \mathrm{cSt}$ PDMS autoejected from same $10 \times 10$ array impacting a smooth PMMA plate. The first large droplets impinge on much smaller preliminary drops and adhere to the plate providing a surface for subsequent drops to impact and rebound, impact and partially coalesce, or impact and coalesce depending on impact velocity and angle. Image at $1.05 \mathrm{~s}$ into drop tower test. c Droplet swarm of 2 cSt PDMS auto-ejected from same $10 \times 10$ array directed toward a 3D sawtooth-featured 'rough' surface. The surface is designed to capture and hold incoming droplets of which it succeeds $99.7 \%$. Image at $0.8 \mathrm{~s}$ into drop tower test
Fig. 7 a Exploded isometric view of U-tube droplet shooter CAD model with material specified. b Orthographic front and section view of assembled U-tube channel. Key dimensions (in millimeters) are provided, and air vent (in and out of the page) is labeled

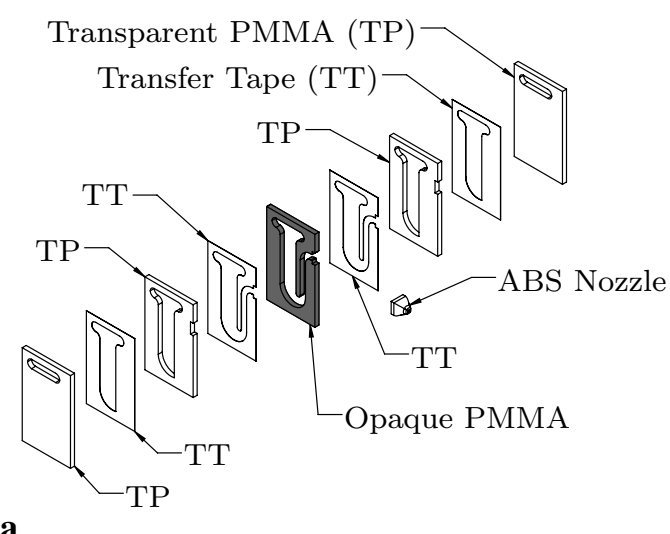

a

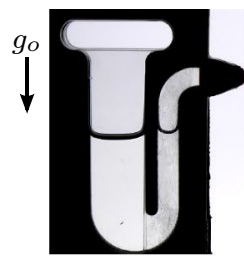

$t=0 \mathrm{~s}$

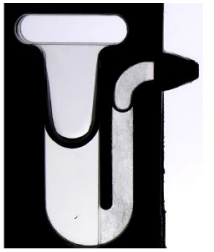

$0.17 \mathrm{~s}$

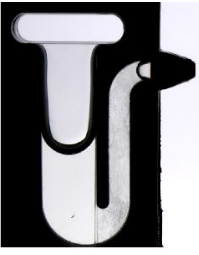

$0.33 \mathrm{~s}$

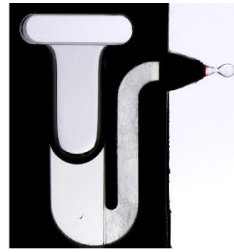

$0.53 \mathrm{~s}$

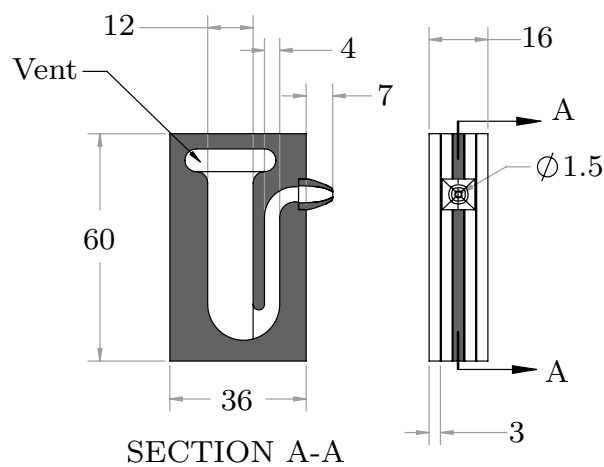

b

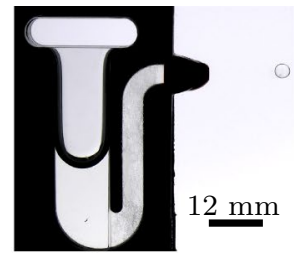

$0.68 \mathrm{~s}$
Fig. 8 Image sequence of U-tube droplet shooter during drop tower test. The 3:1 curvature ratio between the two sides of the U-tube provides sufficient capillary pressure difference to pump the liquid along the small tube where it is accelerated in the nozzle ejecting a single

sheets of 3-mm-thick PMMA. A vent allowing the large leg to breathe is identified in Fig. 7b. The middle layer is opaque black, and the test cell is backlit during drop tower $15-\mu 1$ droplet of $0.65 \mathrm{cSt}$ PDMS horizontally at $0.021 \mathrm{~m} / \mathrm{s}$. Select images at time $t=0,0.17,0.33,0.53$, and $0.68 \mathrm{~s}$ are shown after onset of weightlessness

tests. Figure 8 shows the U-tube ejector partially filled with a wetting liquid, in this case combustible $0.65 \mathrm{cSt}$ PDMS (ref. Table 1). The step reduction in gravity during the drop 

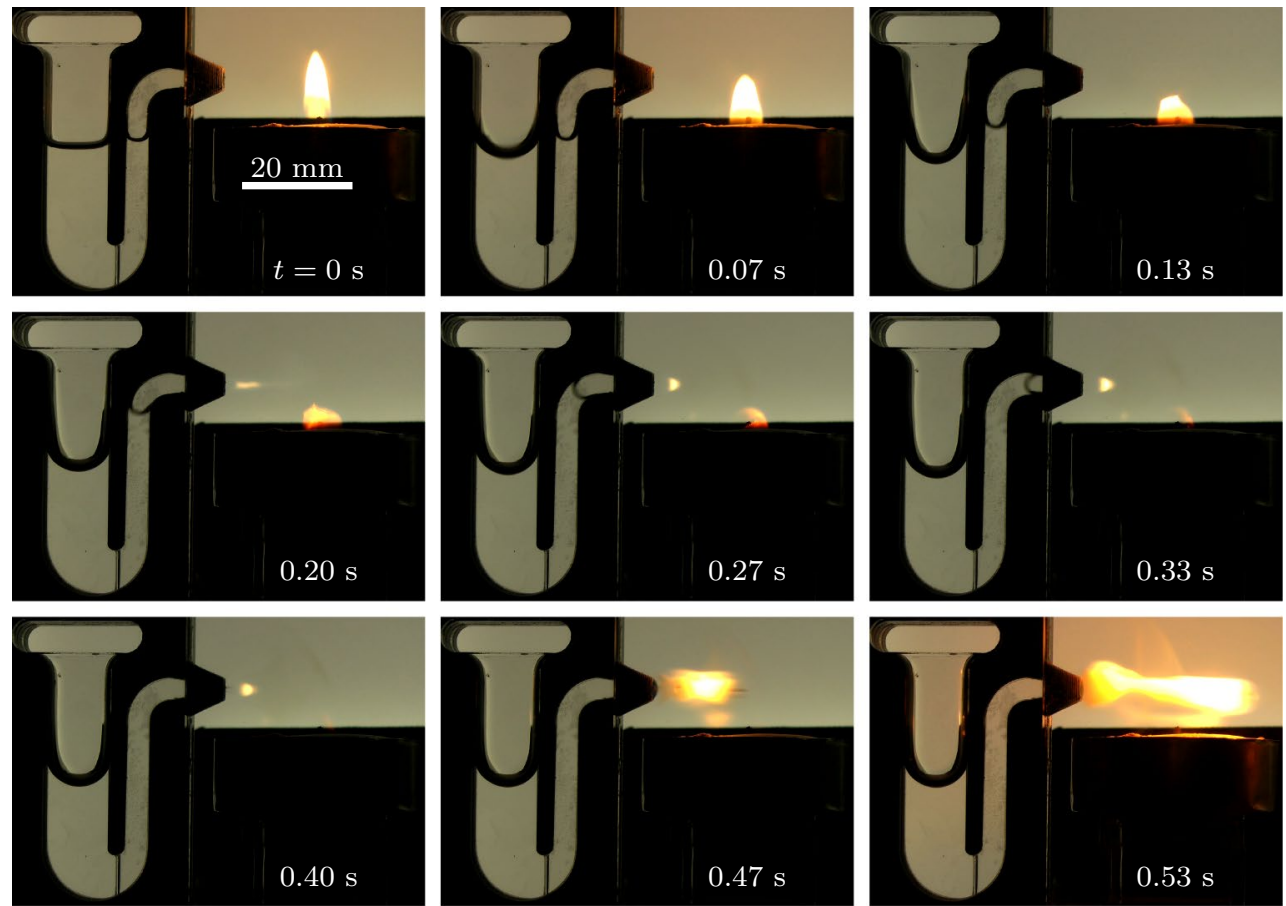

Fig. 9 Ignition sequence of perfectly wetting $0.65 \mathrm{cSt}$ PDMS ejecting horizontally toward and through a candle flame from a U-tube

Fig. 10 Different flame shapes and solid soot trails of lit $2.3-\mu 1$ 0.65 cSt PDMS droplets traveling at a 0.153 , b 0.099 , and c $0.018 \mathrm{~m} / \mathrm{s}$
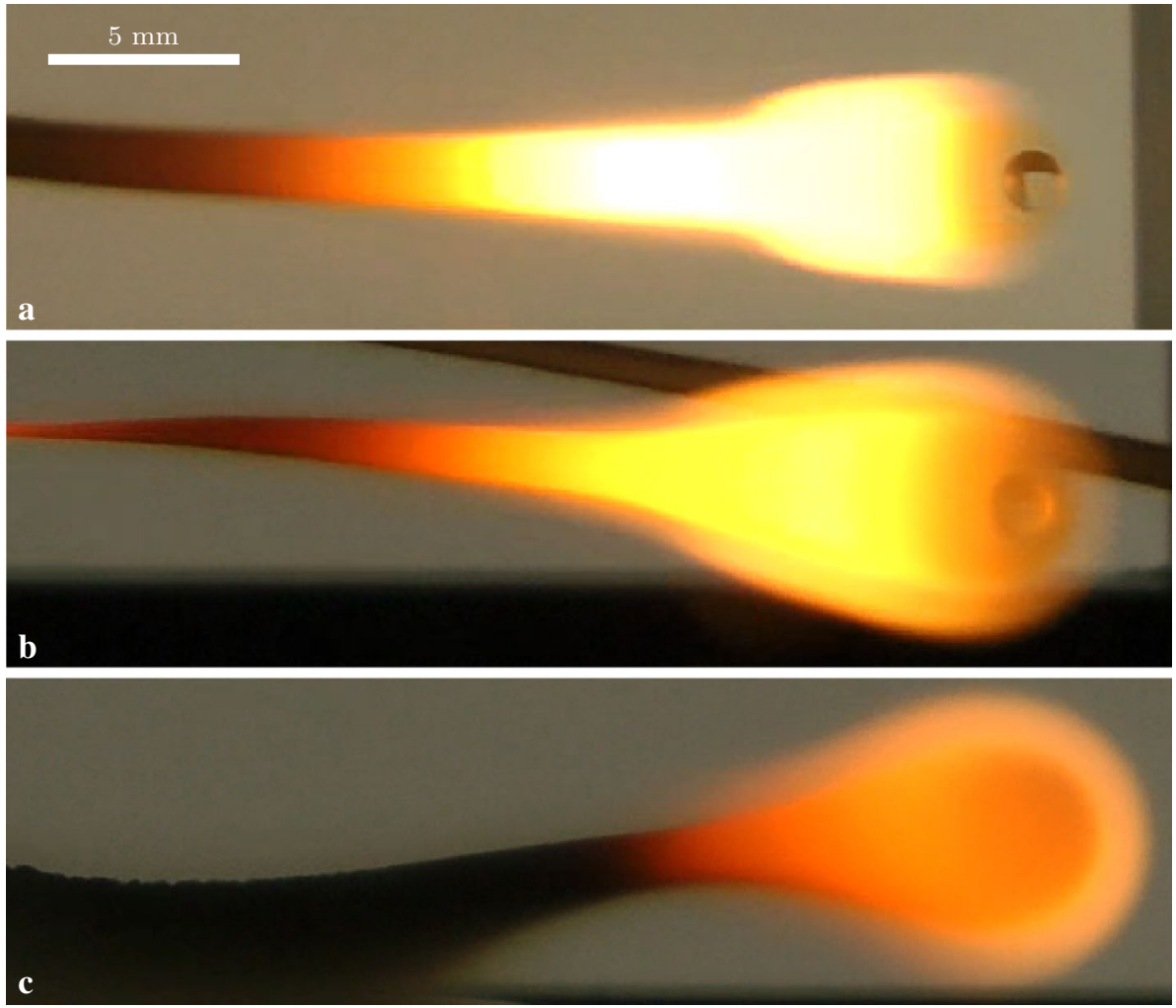


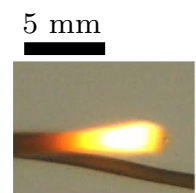

$t=0.93 \mathrm{~s}$

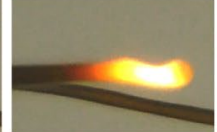

$0.97 \mathrm{~s}$

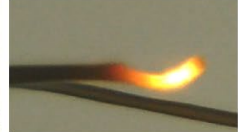

$1.00 \mathrm{~s}$

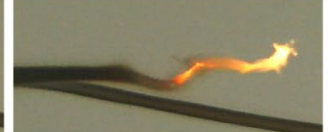

$1.03 \mathrm{~s}$

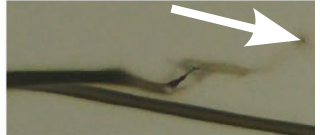

$1.07 \mathrm{~s}$

Fig. 11 Self-extinguish of an initially $0.08-\mu 10.65 \mathrm{cSt}$ PDMS droplet traveling at $0.021 \mathrm{~m} / \mathrm{s}$. A 0.14 -mm-diameter soot shell encapsulating the liquid drop is identified by arrow at right. Images sequence shown at $30 \mathrm{~Hz}$
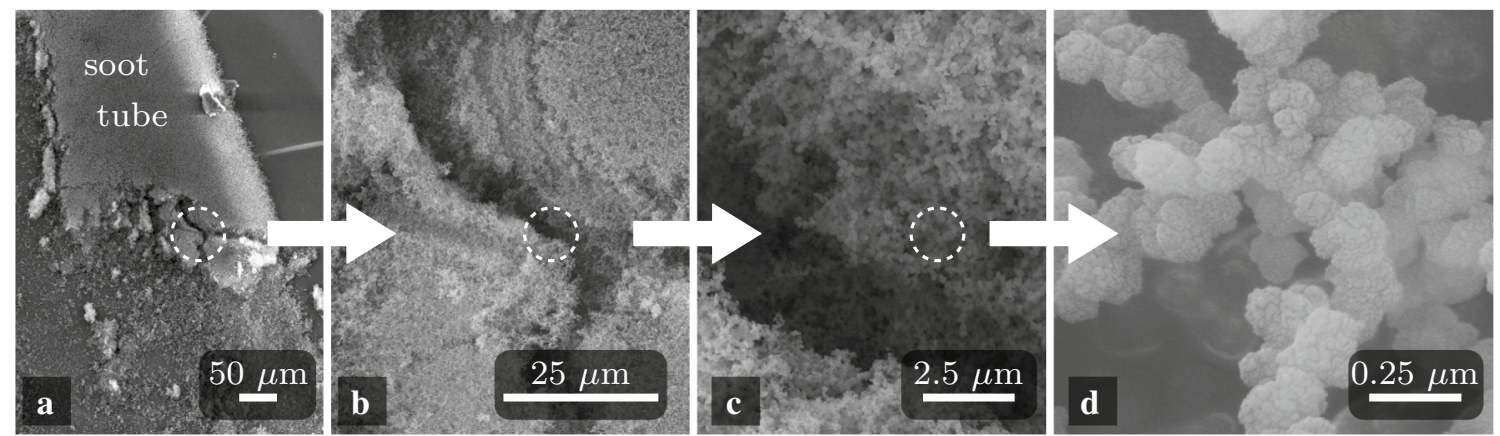

Fig. 12 SEM/TEM images of a flattened, fractured, and crushed soot tube generated while burning an auto-ejected 0.65 cSt PDMS droplet in microgravity conditions. Length scales provided with each image of increasing resolution

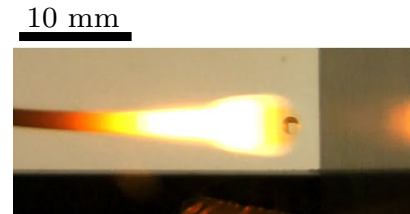

$t=0.70 \mathrm{~s}$

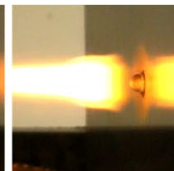

$0.73 \mathrm{~s}$

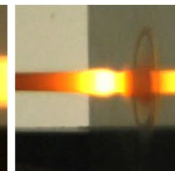

$0.77 \mathrm{~s}$

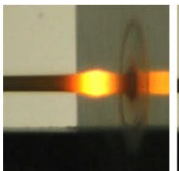

$0.80 \mathrm{~s}$

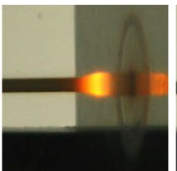

$0.83 \mathrm{~s}$

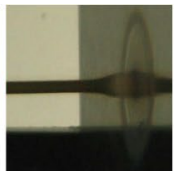

$0.87 \mathrm{~s}$
Fig. 13 Extinguishment of a 2.3- $\mu 1,0.65 \mathrm{cSt}$ PDMS droplet impacting a wall at $0.153 \mathrm{~m} / \mathrm{s}$. The droplet impacts, spreads, and adheres itself to the wall. The solid soot trail is driven into the wall behind the

tower test enables the narrower leg with higher capillary curvature to passively drive the liquid ahead toward the narrower leg exit. The 3D-printed ABS nozzle at the exit assures horizontal auto-ejection as shown in Fig. 8. Wellcontrolled single, double, or trains of drops are readily established at any orientation using this approach.

In Fig. 9, the same U-tube channel of Figs. 7 and 8 aims at a lit candle. Following release of the experiment into free fall, the spontaneous capillary flow displaces combustible gas ahead of the narrow channel meniscus. This gas forms a jet that reaches the candle and immediately back-ignites the nozzle, during which time the candle often self-extinguishes due to the lack of buoyancy during the drop test. When the liquid eventually auto-ejects, an ignited droplet emerges that traverses horizontally across the field of view. Flame front dynamics, combustion rates, drop velocities, combustion products, extinction limits, droplet by inertia and often buckles. In some cases, the combusting drops rebound off the wall. Image sequence shown at $30 \mathrm{~Hz}$

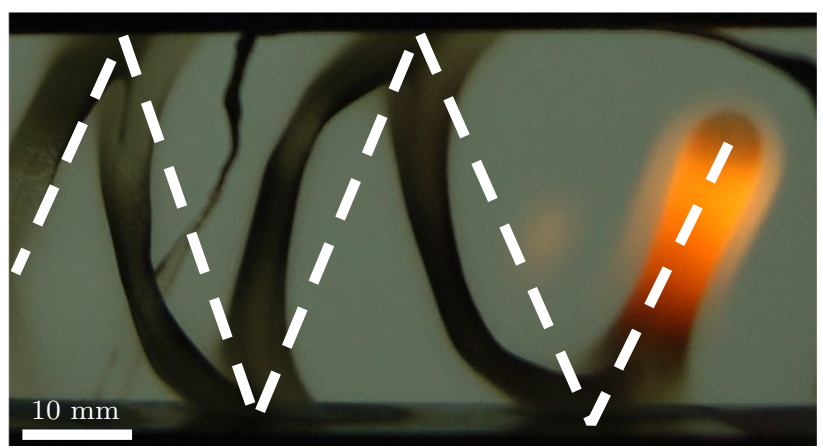

Fig. 14 Lit $2.5-\mu 1,0.65 \mathrm{cSt}$ PDMS droplet bouncing between two preheated parallel steel plates. The initial droplet velocity of $0.100 \mathrm{~m} / \mathrm{s}$ slows to $0.080 \mathrm{~m} / \mathrm{s}$ as energy is lost at each impact. The soot trail is not flexible and breaks near the wall where the lit drop reverses direction. The flame also appears to die out when the drop is close to the wall further weakening the soot tube 
and other characteristics of the convective low-g combustion process are readily identified from such experiments (Marchese et al. 1996; Dietrich et al. 2014). As examples, flame front profiles as functions of droplet speed are shown in Fig. 10, while the unsteady 'flickering' fate of a small droplet near the extinction limit is shown in Fig. 11. An interesting feature of such tests is the soot trail that forms in the wake region of the drop. Without the mixing effects of natural convection, the electrically charged soot forms a rigid tube behind the drop as if extruded during the combustion process. The tube may bend, buckle, flatten, and fracture due to mechanical and hydrodynamic forces that are most pronounced during the $14 g_{0}$ impact at the end of the drop tests. Such structures are collected for further study. In most cases, SEM/TEM images of the tubes reveal a charged fractal carbon structure within the tube walls as
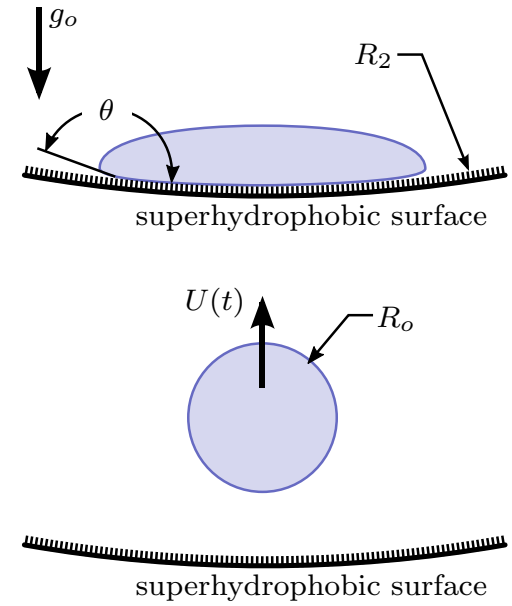

b

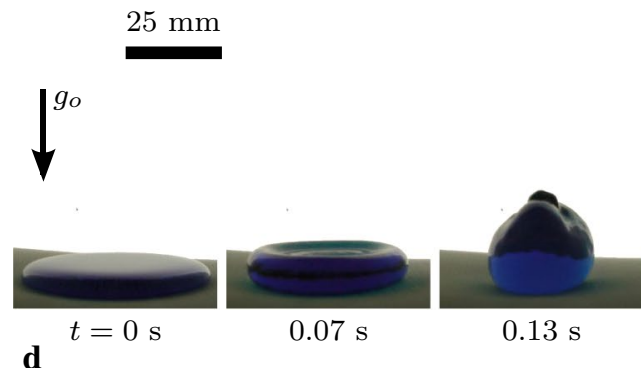

Fig. 15 Schematics (a, b), experiment setup (c), and image sequence (d) of a typical puddle jump drop tower test. a Before the onset of microgravity, a water puddle of volume $V_{\mathrm{d}}$ is resting on a laser-etched PTFE-coated PMMA hydrophobic surface where the contact angle $\theta>130^{\circ}$. The curvature of the surface $R_{2}$ is indicated. b Upon the step reduction in gravity $g_{o}$, the liquid puddle will seek its spherical minimum energy configuration of radius $R_{o}$ and velocity $U$. c The

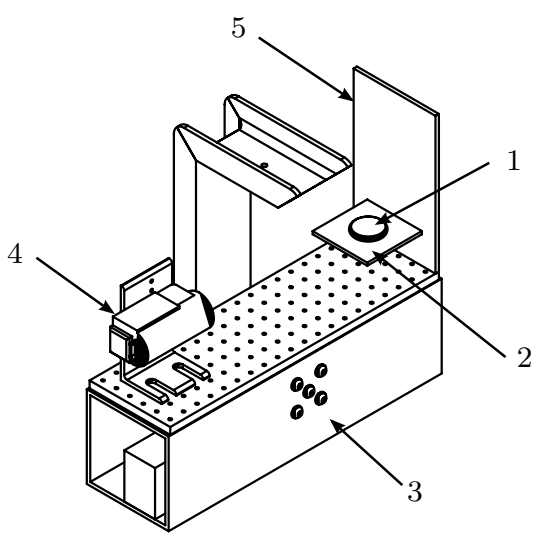

c

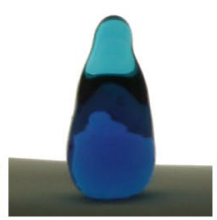

$0.20 \mathrm{~s}$

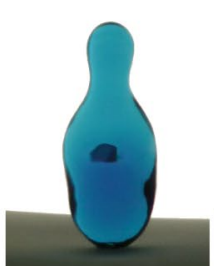

$0.27 \mathrm{~s}$

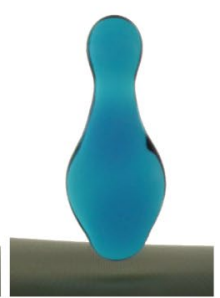

$0.33 \mathrm{~s}$ liquid puddle (1) centered on a superhydrophobic surface (2) placed on the experiment rig (3) between the camera (4) and backlight (5). d Image sequence of a $10-\mathrm{ml}$ dyed water puddle initially at rest on a laser-etched PTFE-coated PMMA hydrophobic surface. Upon entrance into the free fall state of the drop tower test, a capillary wave rolls up the puddle colliding at its center. Inertia generated during the process is sufficient to kick the 'droplet' off the surface

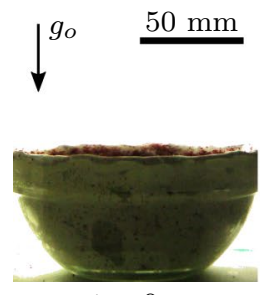

$t=0 \mathrm{~s}$

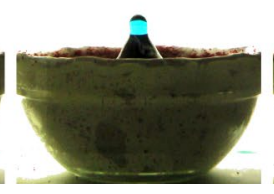

$0.33 \mathrm{~s}$

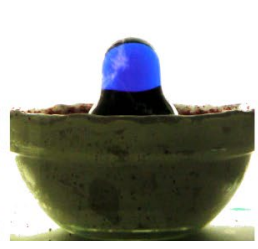

$0.66 \mathrm{~s}$

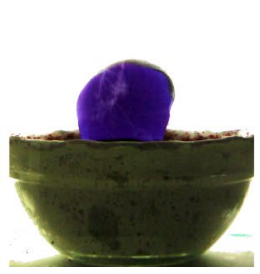

$1.00 \mathrm{~s}$

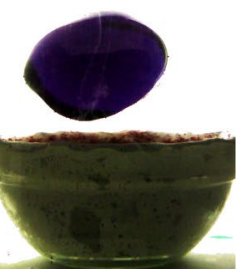

$2.01 \mathrm{~s}$

Fig. 16 A 100-ml water droplet jumps from sand (silica sand exposed to dimethyloctadecylchlorosillane vapors)-impregnated putty-coated bowl $\left(\theta \approx 147^{\circ}\right)$ (Vitz 1990). Image taken $1.7 \mathrm{~s}$ into the drop tower test 
shown in Fig. 12 for a flattened tube. Impacts of combusting droplets produced by the auto-ejection mechanism are also observed. In Fig. 13, a burning drop is extinguished as it nears and impacts a wall, the soot tube anchoring to the wall in the process. In Fig. 14, the oblique auto-ejection of a burning droplet into a parallel slot of preheated steel plates illustrates how such combusting droplets bounce from certain surfaces in a manner reminiscent of
Fig. 17 a Four 1-ml water droplets jumping out of PTFE-coated MJP 3D-printed superhydrophobic curved bowls. From left to right $\mathcal{R}=0.2,0.4,0.6$, and 0.8 and $U=0.022,0.047,0.080$, and $0.102 \mathrm{~m} / \mathrm{s}$. Overlaid images shown at $10 \mathrm{~Hz}$ from just before onset of microgravity till $1.5 \mathrm{~s}$ into drop tower test. b Sectional views of the bowls, feature details, and key dimensions (in millimeters)

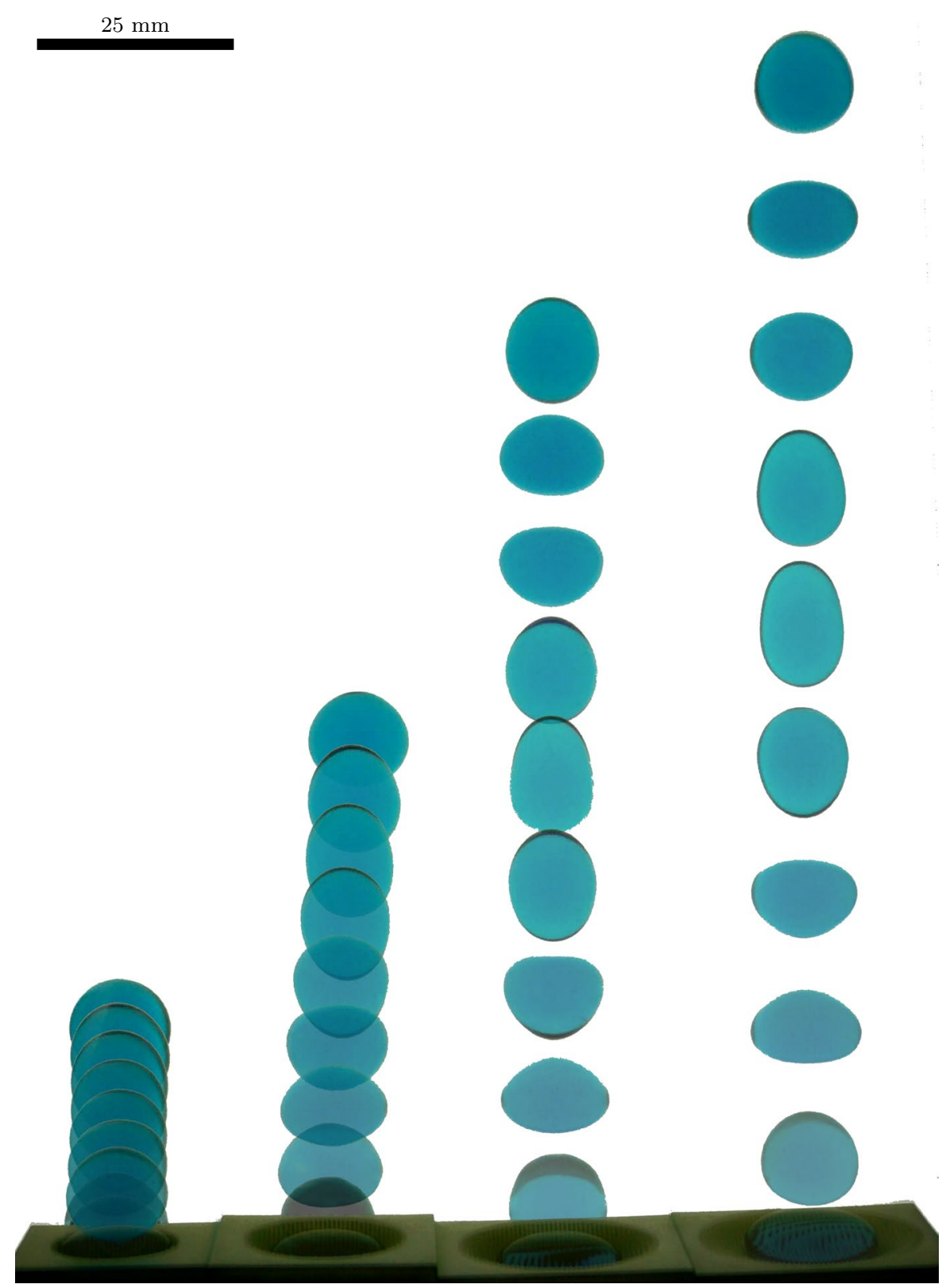

a

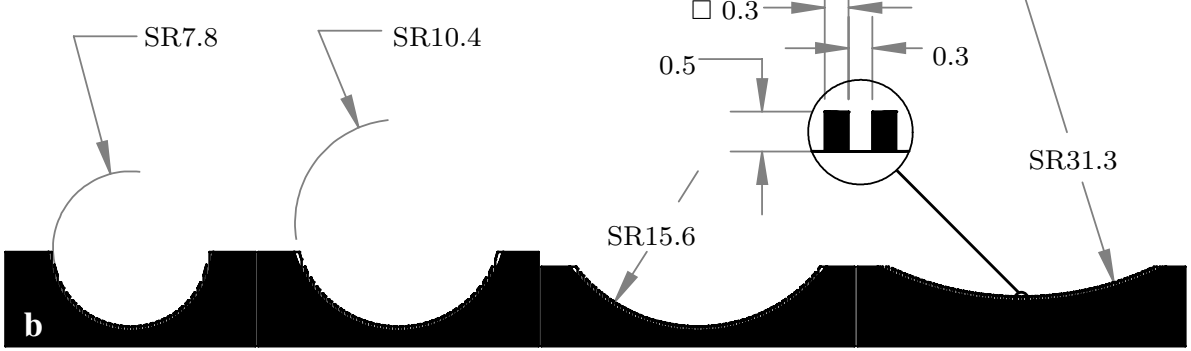


Leidenfrost behavior (Leidenfrost 1756). The droplet path line is shown using a white dashed line. The rigid soot tube cannot follow this trajectory and is forced to bend where it is observed to thin, buckle, and tear. We also note that the droplet appears to extinguish prior to impact with each wall, only to glow brightly as it moves away from the wall.

\section{Puddle jumping and bubble jumping}

The auto-ejection mechanism provides a simple, lowcost, passive, repeatable, and variable droplet-on-demand method for uniquely large droplet dynamics investigations using drop towers. It is enabled by the step reduction in $g$-level afforded by the drop tower. However, it does not function for poorly wetting or poorly non-wetting fluids with large contact angle hysteresis. For highly non-wetting fluids, we demonstrate what we call the 'puddle jumping' auto-ejection approach.

In Fig. 15d, a 10-ml 'puddle' of water is placed on a laser-etched PTFE-coated PMMA sheet with effective contact angle $\theta \approx 148^{\circ}$. The system is placed on a stage and dropped in the drop tower. As the liquid seeks a free interface shape of constant curvature, it de-wets from the surface kicked off by its own inertia and the vertical asymmetry due to the presence of the wall, in effect, performing an auto-ejection function. This process was first reported for immiscible liquids (mercury in $\mathrm{HCl}$ ) in drop tower tests performed by Kirko et al. (1970). The process is similar to the second half of droplet bounce phenomena from superhydrophobic surfaces (Richard et al. 2002). Many of the experimental results shown herein were presented by Weislogel (2012). A numerical investigation is pursued by Zhang et al. (2014). For a 2.1-s drop tower and for predominately aqueous solutions with contact angles $\gtrsim 130^{\circ}$, we demonstrate drop jump volumes between 0.2 and $400 \mathrm{ml}$ corresponding to velocities between 0.020 and $0.120 \mathrm{~m} / \mathrm{s}$. The hydrophobic free surface shape plays a significant role in the drop recoil and jump dynamics. For example, a 100-ml drop jumps within approximately $1.7 \mathrm{~s}$ at $0.023 \mathrm{~m} / \mathrm{s}$ from a bowl coated with a non-wetting sand in Fig. 16. From a flat surface, such a drop jump requires $\tau \sim\left(\rho V_{\mathrm{d}} / \sigma\right)^{1 / 2}=1.7 \mathrm{~s}$ and leaves at $U_{\max } \sim(\sigma g / \rho)^{1 / 4}=0.164 \mathrm{~m} / \mathrm{s}$. Thus, one may tune the jump velocity for a variety of experiments. A single-drop tower test of four drops of equal volume jump from identical substrates of varying curvature is

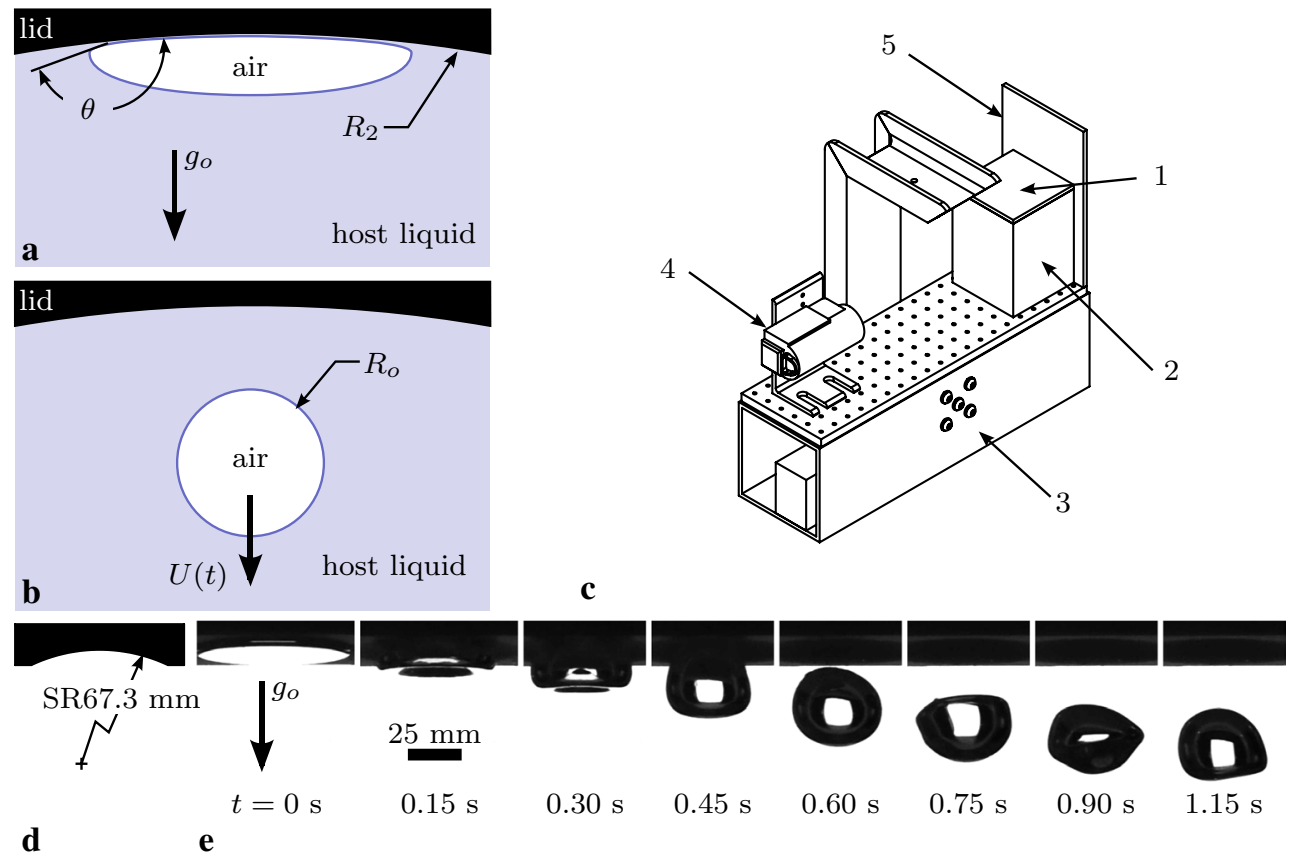

Fig. 18 Schematics (a, b, d), experiment setup (c), and image sequence (e) of a typical bubble jump drop tower test. a Before the onset of microgravity, a buoyancy flattened air bubble of volume $V_{\mathrm{b}}$ against a lid covering a host liquid reservoir. The curvature of the lid is $R_{2}$, and host liquid contact angle with the lid is $\theta=0^{\circ}$. b Upon the step reduction in gravity $g_{o}$, the bubble will seek its spherical minimum energy configuration of radius $R_{o}$ and velocity $U$. c The air bubble resides beneath the lid (1) capping the host liquid reservoir (2) placed on the experiment rig (3) between the camera (4) and backlight (5). d Section view of spherically curved lid used in drop tower test shown in (e). e A $6.7 \mathrm{~Hz}$ time sequence of a $20-\mathrm{ml}$ air bubble in $5 \mathrm{cSt}$ PDMS host liquid. Buoyancy flattens the bubble against the lid $(\mathcal{R}=0.75)$ until gravitational effects are nullified. Similar to the liquid puddle, upon entrance into free fall, the vertical asymmetry of the geometry and desire of the bubble to achieve a spherical configuration act to drive the bubble away from the lid 


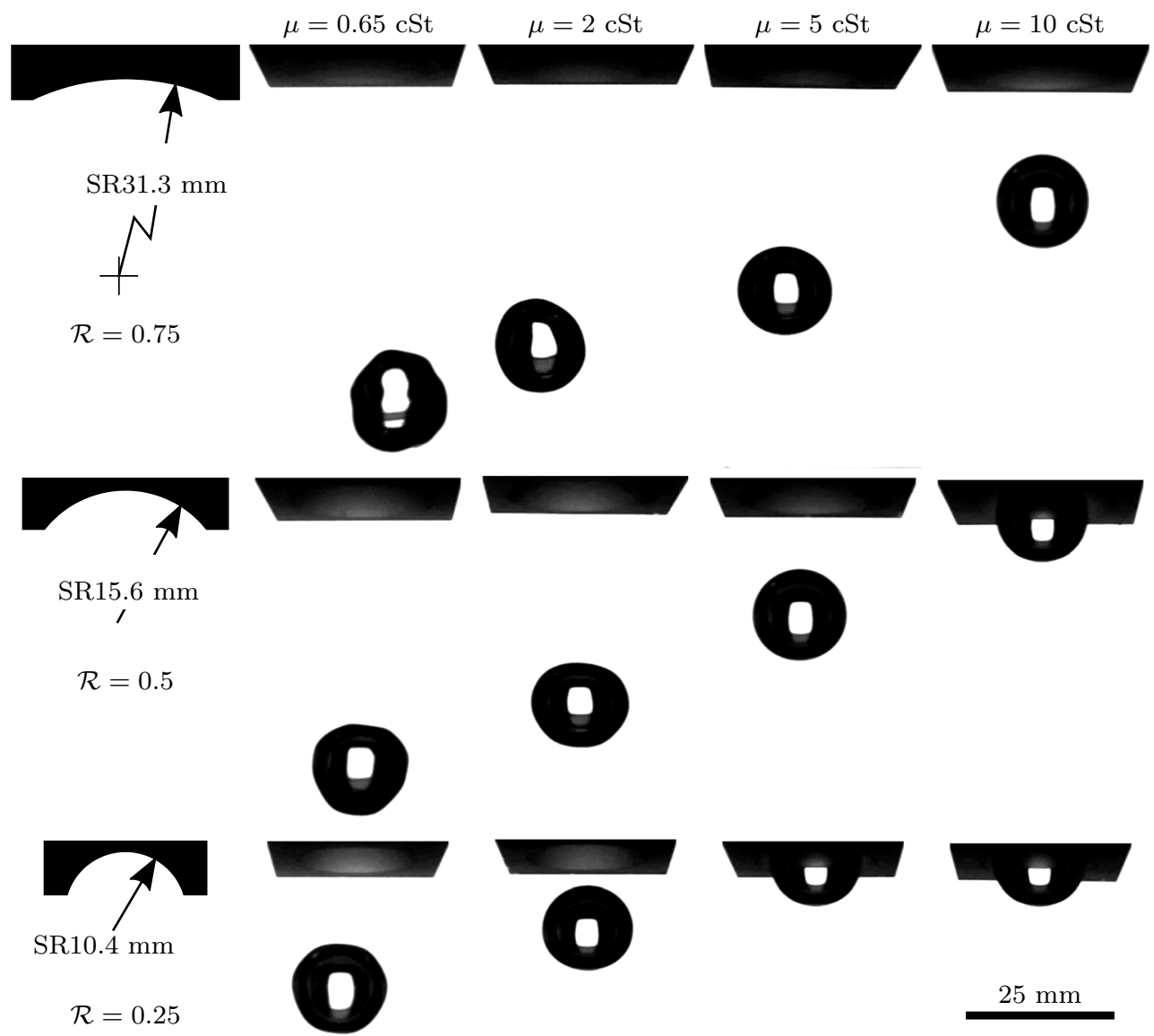

Fig. 19 Comparison of 12.2-ml bubble jump drop tower tests $1.1 \mathrm{~s}$ after free fall begins. Rows show increasing lid curvature (top to bottom), while columns show increasing PDMS host fluid viscosity (left to right). The far left column shows sectional views of lids with key dimensions

shown in Fig. 17. For water, we find that the jump velocity is $U \approx \mathcal{R} / 8 \mathrm{~m} / \mathrm{s}$, where the dimensionless dish curvature $\mathcal{R} \equiv 1-R_{o} / R_{2}$, and where $R_{O}$ is the radius of a spherical drop of volume $V_{\mathrm{d}}$, and $R_{2}$ is the spherical radius of curvature of the dish (Moláček and Bush 2012). The inverse problem of bubbles jumping 'downward' from flat surfaces in drop tower experiments is shown in Figs. 18 and 19. The image sequence in Fig. 18 is of a $20-\mathrm{ml}$ air bubble, which is initially held to the lid due to buoyancy. The lid is 3D-printed with a slight spherical curvature $\left(R_{2}=67.3 \mathrm{~mm}, \mathcal{R}=0.75\right)$ to assure camera-bubble alignment. The bubble jumps off the surface with an initial velocity $U \approx 0.190 \mathrm{~m} / \mathrm{s}$ during the drop tower test. The bubble is significantly slowed to $U \approx 0.120 \mathrm{~m} / \mathrm{s}$ by the end of the 2.1-s test due primarily to host fluid's inertia and viscosity. The impact of host fluid viscosity and lid curvature on the bubble jump process is illustrated in Fig. 19 where still images at $1.1 \mathrm{~s}$ into 12 separate drop tower tests are compared. As expected, bubble jump velocities and distances increase with decreasing liquid viscosity and decreasing lid curvature $(\mathcal{R} \rightarrow 1)$.

\subsection{Minimum drop jump volume}

Provided the surface is sufficiently hydrophobic, in the Cassie state the drop will jump if the drop volume $V_{\mathrm{d}}$ is large enough. The drop volume serves as an indirect measure of Bond number Bo $=\rho g V^{2 / 3} / \sigma$ which in general must rapidly transition $\left(t \ll(\rho V / \sigma)^{1 / 2}\right)$ from Bo $\gtrsim 1$ to Bo $\ll 1$ during the drop tower test. A sample profile image of a typical Cassie state hydrophobic initial condition is shown in Fig. 20 for a $0.025-\mathrm{ml}$ drop $(\mathrm{Bo}=1.2)$. In Fig. 21 is shown a sample drop tower test for drops of varying volume on a single surface. Following the release of the experiment, the largest drop jumps, while the others do not. For water with contact angle $\theta \approx 138^{\circ}$, we find a minimum drop volume below which drop jump does not occur, $0.03 \lesssim V \lesssim 0.1 \mathrm{ml} ; 0.5 \lesssim$ Bo $\lesssim 1.5$. 


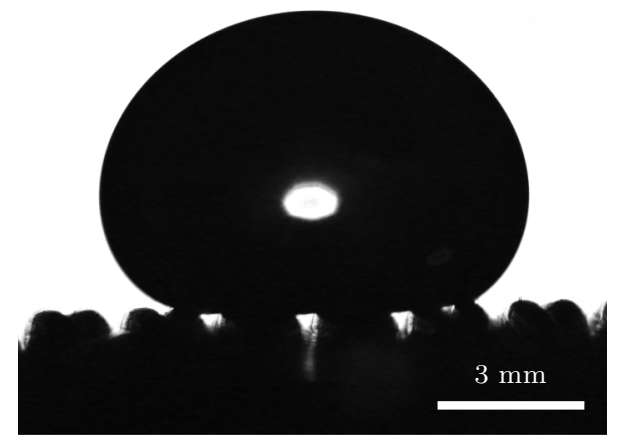

Fig. 20 A $0.025-\mathrm{ml}$ drop of water on PTFE-coated laser-etched PMMA surface

\subsection{Drop jump time scale, maximum puddle volume and speed}

Experiments performed with large puddles corroborate the scale result for the time to roll-up and jump off the surface as $t_{\mathrm{d}} \sim 2.6\left(\rho R_{\mathrm{d}}^{3} / \sigma\right)^{1 / 2}$ (Richard et al. 2002). When $t_{\mathrm{d}}=t_{\mathrm{DT}}$, the maximum drop volume that may be ejected from a surface for the particular drop tower (DT) is reached. For example, we find for our $2.1 \mathrm{~s}$ drop tower that the maximum water drop jump volume is $400 \mathrm{ml}$, which is representative of our scaling estimate of $V_{\mathrm{DT}} \sim \sigma t_{\mathrm{DT}}^{2} / \rho \sim 300 \mathrm{ml}$ for water. Maximum puddle jump speeds are estimated using $U_{\max } \sim(\sigma g / \rho)^{1 / 4} \approx 0.16 \mathrm{~m} / \mathrm{s}$, which are also consistent with maximum experimental velocities of $0.12 \mathrm{~m} / \mathrm{s}$.

\section{Sample puddle jump demonstrations}

\subsection{Drop impacts, rebounds, and heat transfer}

The puddle jump mechanism is readily exploited to study large drop dynamics phenomena. For example, using the general drop jump conditions of Figs. 15, 22a presents an image sequence for a drop tower test of 1-ml dyed water drop impacting and adhering to an aluminum surface with $\theta \approx 58^{\circ}$. The influence of the contact line boundary conditions on the natural frequency and damping rate is key to predicting such characteristics in large capillary systems that cannot be studied in terrestrial laboratories, but are commonly experienced aboard orbiting spacecraft.

In Fig. 22b, the same puddle jump drop deployment method of Fig. 15 is used to impinge again, but this time the impacted surface is slightly warmed, resulting in the drop impacting and adhering to the aluminum surface with $\theta \approx 32^{\circ}$. In Fig. 22c, the plate is heated further and the impacting droplet adheres and boils, with the majority of the liquid leaving the surface not by evaporation, but by droplet ejection due to vapor bubble transport and rupture through the free surface. In Fig. 22d, the plate is heated above the Leidenfrost temperature (Leidenfrost 1756) and the impacting drop rebounds from the surface due to a shielding vapor layer at the leading edge of the drop. While the puddle jump occurs due to hydrophobicity, the similar drop rebound from the heated surface is due to phase change heat transfer. In all such investigations, characteristics such as dynamic drop topology, frequency, oscillation mode, damping, and more may be learned as functions of impact velocity, drop volume, impact angle, wetting angle, and myriad geometric and system-specific variables. Such experiments serve as excellent benchmarks for low-g numerical investigations.

\subsection{Reorientation of complex puddle geometries}

Unique control of the initial configuration of the puddle affords the study of a variety of increasingly complex capillary phenomena. Suggestive examples are presented in Figs. 23 and 24.

In Fig. 23, concentric liquid rings are formed around a single droplet using a hydrophobic mold. During the drop tower test, the liquid bodies jump from the surface with a variety of outcomes. The innermost ring immediately contracts, catches, and engulfs the center droplet in a similar manner as observed by Texier et al. (2013). The outer rings breakup due to the Rayleigh-Plateau instability before they are able to contract to singular drops (Pairam and Fernández-Nieves 2009; McGraw et al. 2010; Yao and Bowick 2011; Nguyen et al. 2012). All rings produce

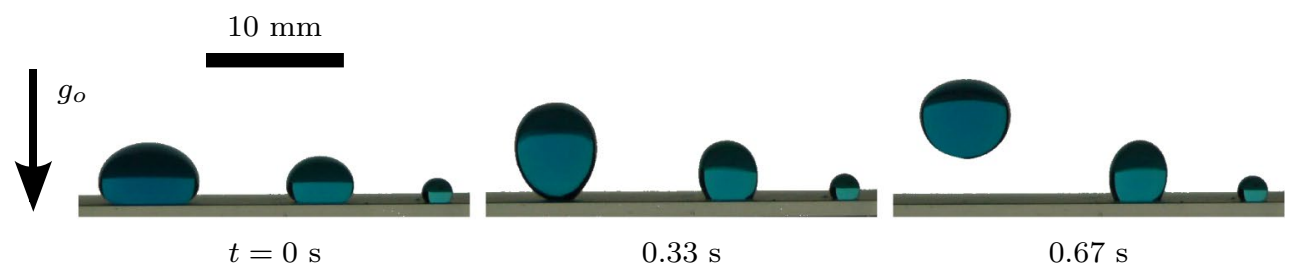

Fig. 21 Drop jump volume threshold for water droplets of $V_{\mathrm{d}}=0.1,0.03$, and $0.005 \mathrm{ml}$ and $\mathrm{Bo}=1.5,0.5$, and 0.2 left to right. Images shown at $30 \mathrm{~Hz}$ 


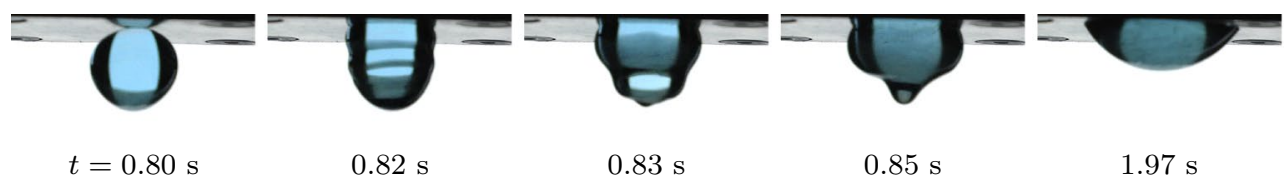

$\mathbf{a}$

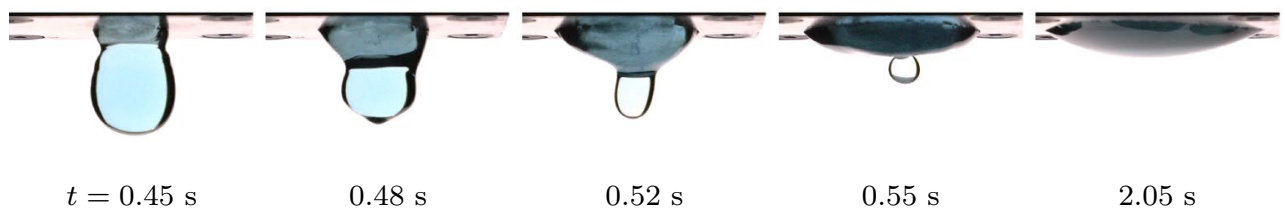

b

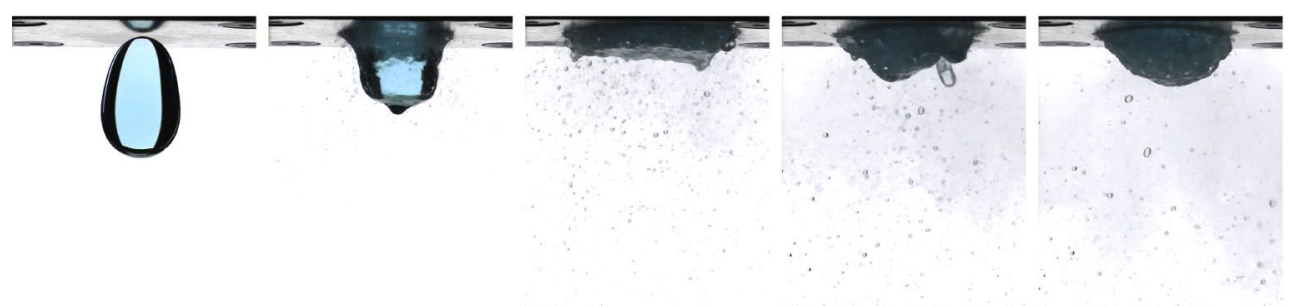

$10 \mathrm{~mm}$

$t=0.58 \mathrm{~s}$

$0.63 \mathrm{~s}$

$0.70 \mathrm{~s}$

$0.77 \mathrm{~s}$

$0.83 \mathrm{~s}$

C

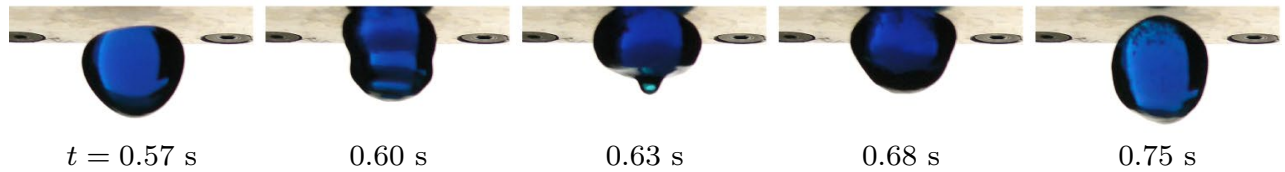

d

Fig. 22 Puddle jump method of Fig. 15 is used to impact 1-ml water droplets on a polished aluminum surface of various temperatures in a microgravity environment: a Impact and adhesion to the room temperature plate with $\theta \approx 58^{\circ}$. b Impact and adhesion to a slightly warmed plate where $\theta \approx 32^{\circ}$. c Impact and adhesion to a further heated plate. The drop boils ejecting large droplets due to vapor bubble transport and rupture through the free surface. d Impact and rebound from a plate heated above the Leidenfrost temperature. Small vapor bubbles are observed in the rebounding drop
Fig. 23 Top view of a concentric ring puddle jump of green dyed water. Images at $10 \mathrm{~Hz}$ (left to right, top to bottom)

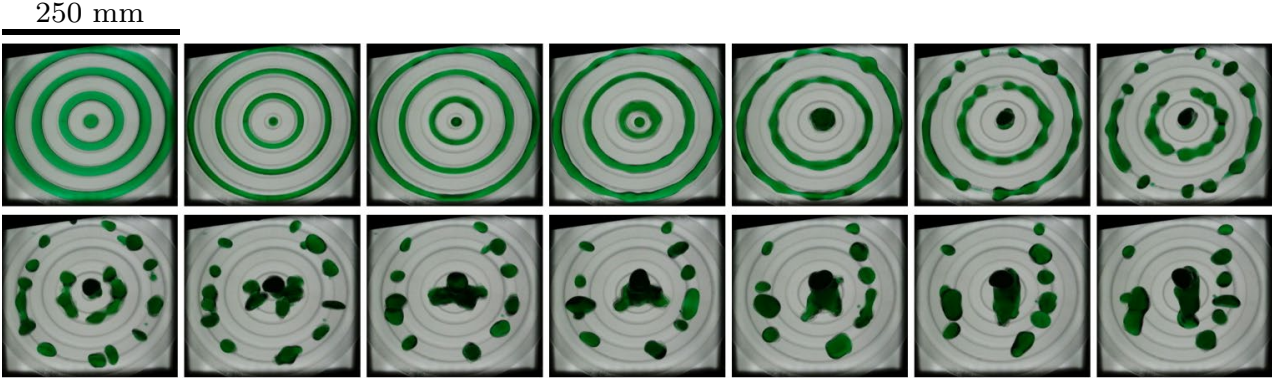

drops that drift inward toward the ring axis. A complex puddle jump is shown in Fig. 24 where inflections in rivulets send ruptured drops in different directions. Specifically, four drops are sent diagonally outwards at the corners, while four larger spinning drops merge inwards into a nearly centered spinning blob. All liquid bodies jump away from the surface at velocities less then that for a flat surface. 


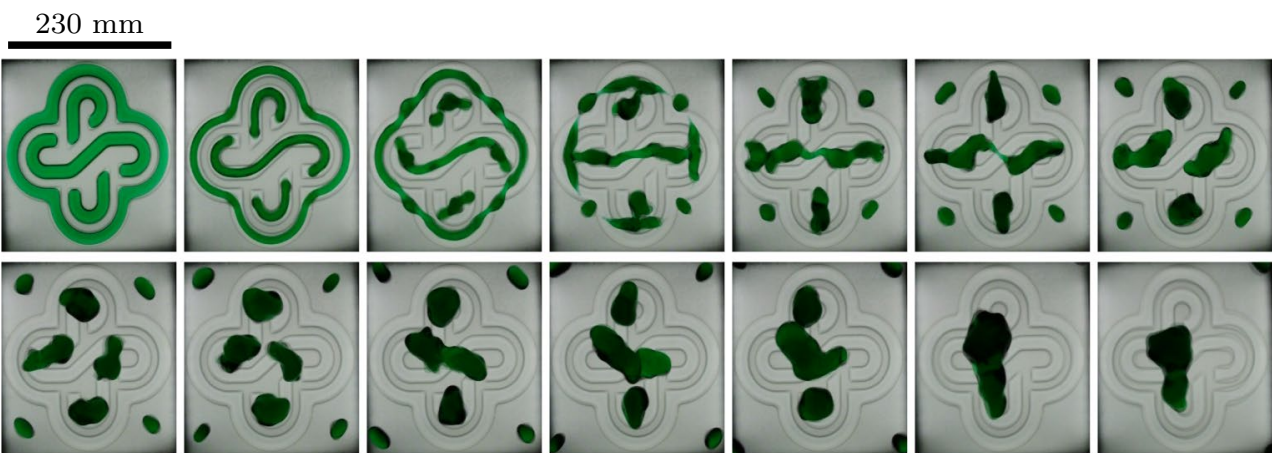

Fig. 24 Top view of a complex puddle jump from an undulating rivulet pattern of green dyed water. Images at $7.7 \mathrm{~Hz}$ (left to right, top to bottom)

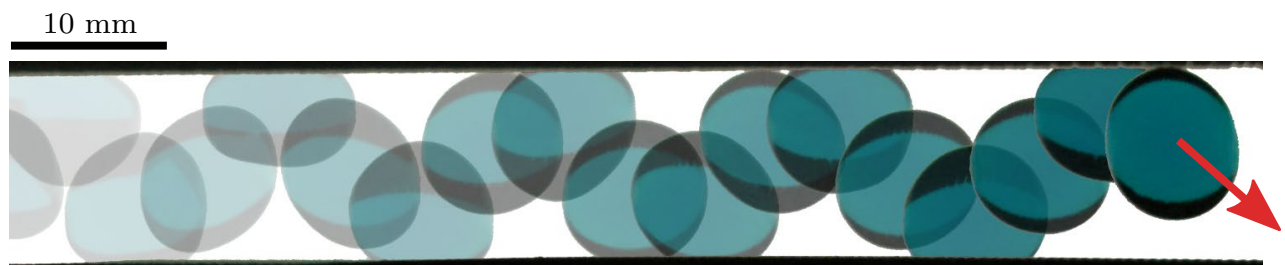

$\mathbf{a}$

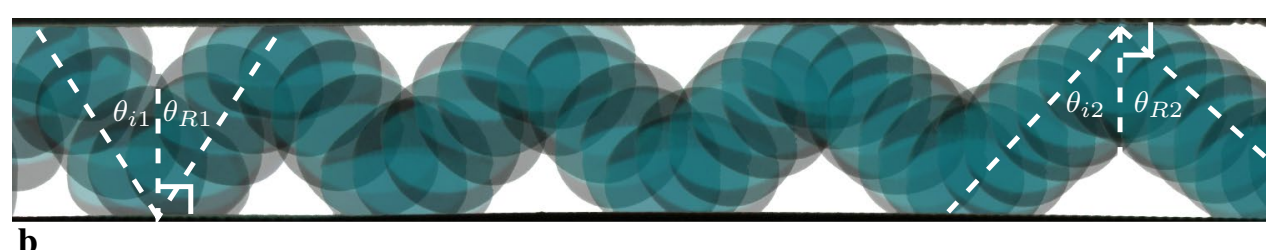

Fig. 25 a A 0.3-ml water droplet produced by oblique drop jump bounces between two superhydrophobic surfaces. The drop bounces 10 times over the course of the 2.1-s drop tower test. Overlaid images at $12.5 \mathrm{~Hz}$. Red arrow indicates direction of continued travel. b Over- lay of images at $33 \mathrm{~Hz}$ reveals changes in incidence and reflection angles for the same drop test. Over the course of 8 bounces $\theta_{i}+\theta_{R}$ increases from $\approx 68^{\circ}$ to $\approx 104^{\circ}$ and the velocity of the drop decreases from 0.226 to $0.177 \mathrm{~m} / \mathrm{s}$

Fig. 26 Red and blue 3-ml jumping water droplets that rebound obliquely from two hydrophobic surfaces. The drops then collide off center producing a tumbling containerless mixing operation in a microgravity environment. Overlaid images at $t=0,0.02$, $0.55,0.931 .30$, and $1.72 \mathrm{~s}$ into the drop tower test
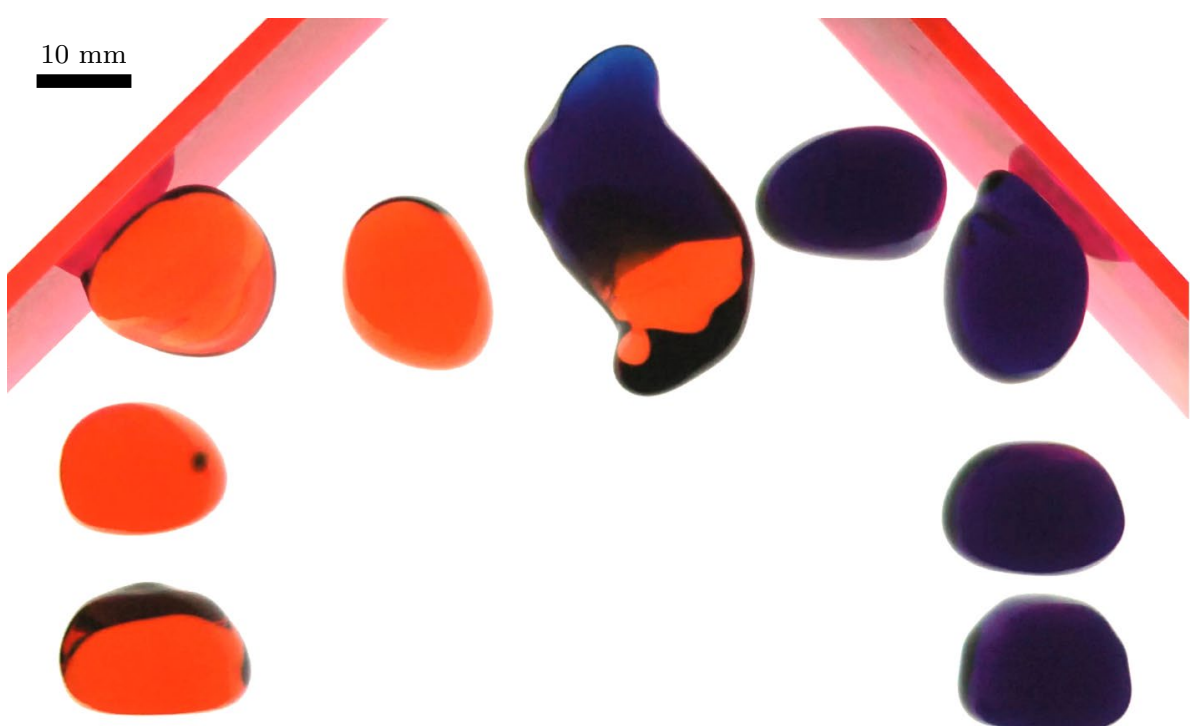
Fig. 27 A 3-ml jumping puddle that is redirected to collide with a partially wetted $13-\mathrm{mm}$ figurine resting on a second hydrophobic surface. Such demonstrations suggest methods for passive low-g containerless processing. Overlaid images at $t=0,0.20,0.38,0.680 .90,1.42$ and $1.85 \mathrm{~s}$ into the drop tower test

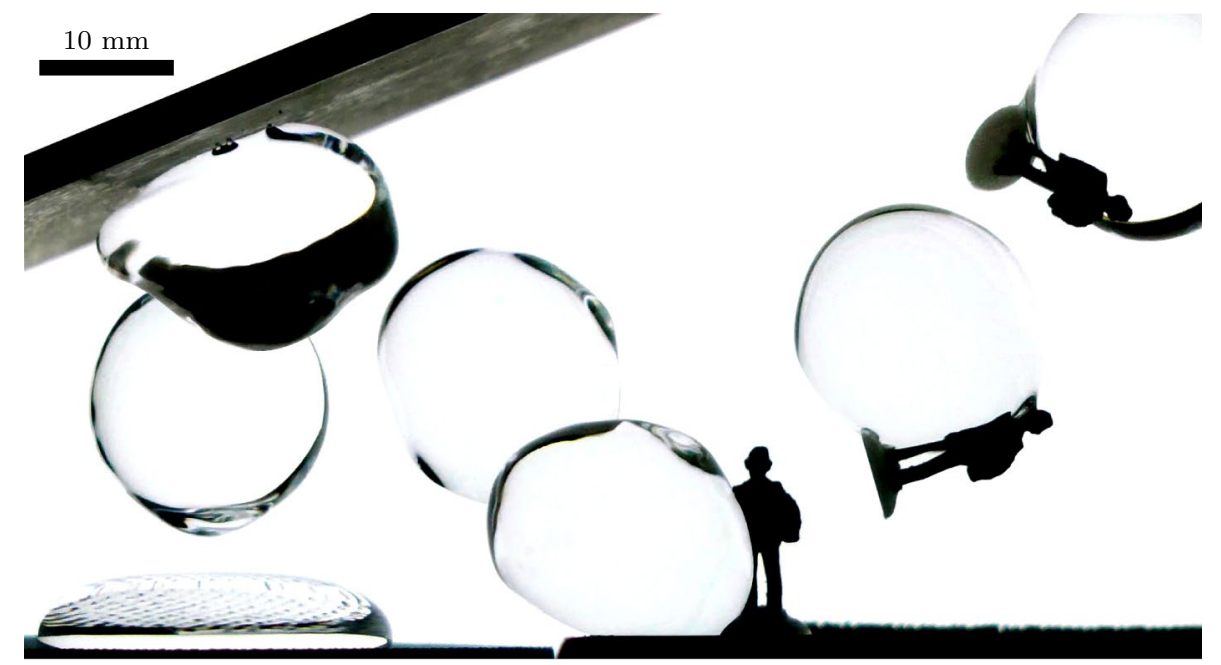

\subsection{Large droplet fluidics}

The puddle jump ejection method may also readily be applied to large drop fluidics problems in further drop tower tests. Selections of examples are demonstrated here. In Fig. 25, similarly as in Fig. 14, a vertical puddle jump enters a parallel hydrophobic pathway at an oblique angle. Coefficients of restitution are readily determined from such data shedding light on viscous dissipation and the impact of surface topology, hydrophobicity, and gas phase participation for such large drops. In Fig. 26, two jumping puddles are redirected for large drop impact studies. In Fig. 27, a 3-ml puddle jumps and is redirected by a secondary hydrophobic surface to pickup a partially wetted item, transporting it downstream out of the field of view. A 'bowl-less' fish bowl is demonstrated in Fig. 28 also using the puddle jump technique.

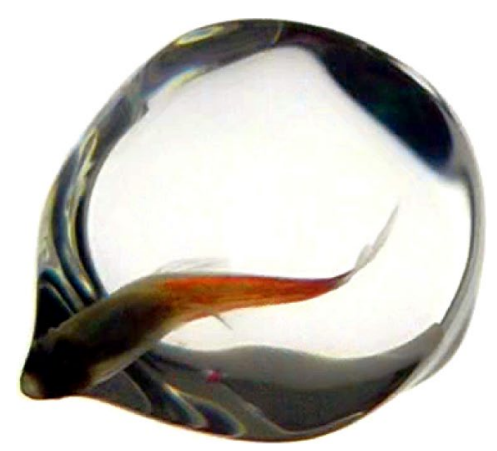

$10 \mathrm{~mm}$

Fig. 28 A neon tetra (Paracheirodon innesi) swims inside a 3-ml jumped puddle. Its repeated decreasingly tentative attempts to swim out of the liquid drop are resisted by surface tension forces that draw the fish back into the perfectly wetting droplet

\section{Summary}

Large droplets can be uniquely studied in reduced-gravity environments. Drop towers provide special control of initial conditions in that gravity serves as a trigger, leading to the auto-ejection of drops from tapered tubes and puddle jumping from flat surfaces. The significantly larger drop volumes produced in the low-g environment result in significantly larger capillary time scales, enabling the use of low-speed (i.e., $60 \mathrm{fps}$ ) HD video photography to capture and quantify a wide range of important dynamic interface behavior. The demonstrations performed herein are presented to inspire new approaches to study both old and new problems. Both the auto-ejection and puddle jump drop tower approaches provide advantages of simple, low-cost, highly controlled, and highly repeatable passive methods to generate droplets with volumes up to $\sim 10,000$ times larger than droplets typically studied in terrestrial laboratories. The drops can be directed in a variety of orientations and with a variety of fluids, velocities, and drop volumes. Capillary tube autoejection phenomena are limited to sufficiently wetting systems, while puddle jump phenomena are limited to sufficiently nonwetting systems.

Acknowledgments This work was in part completed under NASA cooperative agreement NNX09AP66A and NASA/Oregon Space Grant Consortium grant NNX10AK68H, the latter of which was used in part to support A. Wollman and B. Wiles. We also acknowledge the 3D print support of the Xerox Corporation and 3-D Systems.

\section{References}

Chunhui L (1993) Microgravity drop tower facilities. Struct Environ Eng 4:227

Corning D (1998) Product information Dow Corning 200 fluid. http:// webservice.oxygenekatalog.dk/getDoc.aspx?DocID $=11996$. Ref. no. 22-0069N-01 
Dietrich DL, Nayagam V, Hicks MC, Ferkul PV, Dryer FL, Farouk T, Shaw BD, Suh HK, Choi MY, Liu YC et al (2014) Droplet combustion experiments aboard the international space station. Microgravity Sci Technol. doi:10.1007/s12217-014-9372-2

Dittus H (1991) Drop tower 'Bremen': a weightlessness laboratory on earth. Endeavour 15(2):72

Kirko I, Dobychin E, Popov V (1970) Phenomenon of the capillary. Sov Phys Dokl 15:442

Leidenfrost JG (1756) De aquae communis nonnullis qualitatibus tractatus. Ovenius, Duisburg

Lekan J, Neumann E, Sotos R (1993) Capabilities and constraints of NASA's ground-based reduced gravity facilities In: The second international microgravity combustion workshop (SEE N9320178 07-29), vol 1, pp 45-60

Marchese A, Dryer F, Colantonio R, Nayagam V (1996) Microgravity combustion of methanol and methanol/water droplets: Drop tower experiments and model predictions. In: Symposium (international) on combustion, vol 26. Elsevier, pp 1209-1217. http:// www.sciencedirect.com/science/article/pii/S0082078496803377

McGraw JD, Li J, Tran DL, Shi AC, Dalnoki-Veress K (2010) Plateau-Rayleigh instability in a torus: formation and breakup of a polymer ring. Soft Matter 6:1258. doi:10.1039/B919630G

Mehrabian H, Feng JJ (2014) Auto-ejection of liquid drops from capillary tubes. J Fluid Mech 752:670

Meseguer J, Sanz-Andrés A, Pérez-Grande I, Pindado S, Franchini S, Alonso G (2014) Surface tension and microgravity. Eur J Phys 35(5):055010. http://stacks.iop.org/0143-0807/35/i=5/ $\mathrm{a}=055010$

Moláček J, Bush JW (2012) A quasi-static model of drop impact. Phys Fluids (1994-present) 24(12):127103. http://scitation.aip. org/content/aip/journal/pof2/24/12/10.1063/1.4771607

Nguyen TD, Fuentes-Cabrera M, Fowlkes JD, Diez JA, González AG, Kondic L, Rack PD (2012) Competition between collapse and breakup in nanometer-sized thin rings using molecular dynamics and continuum modeling. Langmuir 28(39):13960. doi:10.1021/ la303093f

Pairam E, Fernández-Nieves A (2009) Generation and stability of toroidal droplets in a viscous liquid. Phys Rev Lett 102(23):234501. doi:10.1103/PhysRevLett.102.234501
Richard D, Clanet C, Quéré D (2002) Surface phenomena: contact time of a bouncing drop. Nature 417(6891):811. http://www. nature.com/nature/journal/v417/n6891/abs/417811a.html

Snyder TJ, Andrews M, Weislogel M, Moeck P, Stone-Sundberg J, Birkes D, Hoffert MP, Lindeman A, Morrill J, Fercak O et al (2014) 3D systems' technology overview and new applications in manufacturing, engineering, science, and education. 3D Print Addit Manuf 1(3): 169

Steinberg T (2008) Reduced gravity testing and research capabilities at new 2.0 second drop tower. J Achiev Mater Manuf Eng 31(2):822

Suñol F, González-Cinca R (2011) Droplet collisions after liquid jet breakup in microgravity conditions. J Phys Conf Ser 327(1):012026. http://stacks.iop.org/1742-6596/327/i=1/a=012026

Texier BD, Piroird K, Quéré D, Clanet C (2013) Inertial collapse of liquid rings. J Fluid Mech 717:R3. http://journals.cambridge.org/ abstract_S0022112013000153

Vitz E (1990) Magic sand: modeling the hydrophobic effect and reversed-phase liquid chromatography. J Chem Educ 67(6):512. doi:10.1021/ed067p512

Weislogel MM (2012) Recent capillary fluid research relevant to spacecraft system design. In: 7th International symposium on two-phase systems for ground and space applications. Beijing, China, 17-21 Sept 2012

White FM, Corfield I (2006) Viscous fluid flow, vol 3. McGraw-Hill, New York

Wollman A (2012) Capillarity-driven droplet ejection. Master's thesis, Portland State University. http://archives.pdx.edu/ds/psu/8243

Wollman A, Weislogel M (2013) New investigations in capillary fluidics using a drop tower. Exp Fluids 54(4):1. doi:10.1007/ s00348-013-1499-1

Yao Z, Bowick M (2011) The shrinking instability of toroidal liquid droplets in the Stokes flow regime. Eur Phys J E 34(3):32. doi:10.1140/epje/i2011-11032-9

Zhang L, Li ZD, Zhao JF (2014) Rebound of liquid droplets caused by sudden decrease of gravity. Interfacial Phenom Heat Transf 2(1):41 